\title{
Measuring the Negative Externalities of a Private Leisure Activity: Hooligans and Pickpockets around the Stadium
}

\begin{abstract}
Given the recent increase observed in crime related to football matches; we determine the extent to which this private leisure activity is responsible for negative crime externalities. We conduct an Exploratory Spatial Data Analysis and spatial regressions at the census tract level drawing on data for the matches played by Football Club Barcelona and geocoded crime data for the city of Barcelona (Spain); focusing on thefts (mainly pick pocketing) and assaults (interpersonal violence or hooliganism). We find an increase in the number of thefts across the whole city but, especially, in those census tracts within a 700-meter radius of the stadium. These results are confirmed by the low number of crimes committed during away matches in the census tracts around the stadium. A similar spatial pattern is found for assaults. Our results provide evidence of a displacement effect of violent supporters (hooligans) towards the stadium on football days.
\end{abstract}

Key words: Crime, Football, Hooliganism, Negative Externalities, Police Forces, Exploratory Spatial Data Analysis.

JEL Classification: K42, H27, R1, L83

\author{
Daniel Montolio (corresponding author) \\ Universitat de Barcelona - Institut d'Economia de Barcelona (IEB) \\ Facultat d'Economia i Empresa \\ Av, Diagonal 690. Torre 6 Planta 2 \\ 08034 Barcelona (Spain) \\ Phone: (0034) 934039080 \\ Fax (0034) 934031813 \\ e-mail: montolio@ub.edu
}

\author{
Simón Planells-Struse \\ Centro Crímina - Universidad Miguel Hernández \\ Avda. de la Universidad s/n. Edif. Hélike, 03201 Elche (Spain) \\ e-mail: simonplanells@gmail.com
}

Acknowledgements. We would like to thank the Catalan police, Mossos d'Esquadra, for giving us access to the dataset and providing us with very helpful comments and insights regarding the data. We would also like to thank Mr. Sergi Sansano for his excellent research assistance and tireless support in the geocoding process; Xavier-Andoni Tibau for his excellent help in providing accurate and understandable maps; Paolo Buonanno, Camille Hémet, Hannes Mueller and Michel Priks for helpful comments. We would like to specially thank the Editor and the two referees for really useful insights on the paper. Usual disclaimer applies. Daniel Montolio acknowledges support from grant ECO201341886-R and ECO2016-75912-R from the Spanish Ministerio de Economía $y$ Competitividad. 


\section{Introduction}

With over 52 million followers on Facebook, 11 million followers on Twitter and a long history of sporting success, Football Club Barcelona (FCB, hereafter) is one of the world's leading football teams. Its current popularity is reflected in an average gate of over 70,000 spectators at its home games. Indeed, the attraction of FCB would appear to represent a sizeable economic benefit for the well-known city and its citizens. For instance, it seems probable that the club's home matches attract a higher number of tourist arrivals and boost levels of consumption in the retail sector with a consequent positive impact on job creation and tax revenues.

However, despite these positive economic effects, a number of negative externalities may affect the city as a result of its being home to such a major team and its hosting of such large events on a regular basis. Above all, the presence of FCB might promote criminal activity. Large crowds are likely to increase the number of potential targets, thus attracting more offenders, especially those "specialized" in property crimes (such as pick pocketing). Moreover, the increase in the number of social interactions, the high consumption of alcohol combined with the euphoria of a victory or despair of defeat can increase levels of interpersonal violence (Card and Dahl, 2011 and Montolio and Planells-Struse, 2016). Additionally, celebrations may result in other types of illegal behavior, including vandalism and the assault of police officers. These various forms of interpersonal violence are usually known as hooliganism, especially when a sport event is closely related.

Violence related to football matches in Spain has recently attracted the attention of the media outlets and the public opinion in general. The killing of a supporter in an internet planned riot between the radical supporters of Atlético de Madrid (called Frente Atlético) and those of the Deportivo de la Coruña (called Los Suaves) in Madrid the day that both teams were going to play a domestic league match $\left(29^{\text {th }} \text { of November } 2014\right)^{1}$ focused the media attention and raised many questions regarding the negative externalities of football matches on unlawful behavior. Few days later in Barcelona (11 $1^{\text {th }}$ of December 2014), and after a Champions League match played by FCB against Paris Saint Germain, two PSG supporters were stabbed close to the Camp Nou Stadium. ${ }^{2}$ This event fuelled further the discussion regarding the close relation between football and violence (inside and outside

1 http://www.lavanguardia.com/deportes/20141130/54420902745/muere-aficionado-deportivo-ultrasatletico.html (last accessed October 2017).

${ }^{2}$ http://www.lavanguardia.com/sucesos/20141211/54421303752/apunalado-seguidor-psg-camp-nou.html (last accessed October 2017). 
stadiums). ${ }^{3}$ In this sense, and despite the efforts of FCB to eradicate violent behaviour inside the stadium, a violent group of radical FCB supporters (called Boixos Nois) continues to gather outside the stadium on match days to "warm up" the atmosphere. Note, however, that as previously mentioned excitement and alcohol consumption, among others, could also influence violent behaviour of non-radical football fans.

In this situation, most research has attempted to explain the reasons behind both the determinants of local crime rates and the recurring problem of crowd violence during sporting events. Despite the recent predominance of the independent self-maximizing individual ("spatially liberated") perspective in defining what determines individual outcomes such as work, income, educational achievement, welfare or even happiness; location (or cities, or neighborhoods within cities, or communities within neighborhoods, or blocks within communities) still matters because life is decisively shaped by where individuals (decide to) live. In this framework neighborhood effects have long been analyzed, by both sociologists and economists, in models of urban externalities and in models that investigate the role of agglomeration in looking for an understanding of the extent of such effects and especially in looking for the spatial scale over which they operate. In this situation crime has been long recognized, among other things, as an important mechanism behind those observed neighborhood effects. ${ }^{4}$

If the aim is to really understand the strength, spatial scale and mechanisms of neighborhood effects, as it is in our case, there is a need for the spatial perspective to dominate the analysis and, in the case of studying crime, this is even more pronounced given the "urban nature" of crime (see Glaeser et al. 1996) or, in other words, how to explain that crime is too variable across space to be explained only by individual preferences, endowments or incentives. From this perspective, social interactions (or local peer-effects) emerge as a powerful explanation of observed crime rates and provide enough variation across space to explain why otherwise identical locations show very different crime patterns. Social interactions are directly related to density and, hence, the urban context has been taken as the

\footnotetext{
${ }^{3}$ This issue is, unfortunately, well spread around the world and we can find many (recent) examples in countries such Argentina and Chile (http://www.marca.com/2015/02/17/futbol/futbol_internacional/argentina/1424213985.html, last accessed October 2017) or in other European cities such as an aggression of Chelsea fans to an individual in the previous hours of a Championship match between PSG and Chelsea. (http://www.elmundo.es/internacional/2015/02/18/54e44545268e3e4a728b4572.html, last accessed October 2017).

${ }^{4}$ Other potential drivers of the neighborhood effects are human capital externalities (e.g. Rauch, 1993), schooling (e.g. Benabou, 1993), social housing (e.g. Currie and Yelowitz, 2000), housing externalities (e.g. Rossi-Hansberg, et al. 2010) or the sharing of goods, labor or ideas by firms (e.g. Ellison et al., 2010).
} 
basic situation in which to analyze the empirical side of the literature on the economics of crime.

Finally, our investigation is a further contribution to the literature dealing with the existence of neighborhood effects and the valuation of amenities (also crucial for understanding processes of gentrification, urban revival within cities or capitalization in housing values). In our case FCB supporters (individuals that share a common characteristic) cluster in a very specific location of the city at very precise moments in time (game time) because of the existence of a temporal amenity. By comparing these "game times" with what happens at the same location when there is no amenity allows us to disentangle the externality or spillover effect coming from the amenity itself. Therefore, this paper not only focuses on an event, a football match, where social interactions (due to agglomeration and/or emotion) can be seen to be prominent, but also deals with an issue that lies at the core of the discussion of the future of cities in developed countries; that is, the location of large-scale events in central cities that bring prosperity but also temporary increases in contagion, congestion and crime. In this sense, the present paper also relates to the economic literature analyzing the impacts of the location of sport stadiums in a city. A common positive empirical result is found on the desirability of the area where the stadium is located basically via inflating sale and rent prices (see, among others, Ahlfeldt and Kavetsos, 2013), omitting the possible negative externalities arising from the criminal activity induced by the sports facility, an externality that we measure in the present paper.

The aim of this paper, therefore, is to conduct an in-depth analysis of the impact of FCB matches on different types of crime in an urban context. The use of geocoded data, the approach adopted and the techniques employed make an innovative contribution to the literature. Our results allow us to characterize in full the impact of the football matches of a leading European team on crime in a major European city.

More specifically, we study the respective impact of FCB's home and away matches on property crime (e.g., thefts) and on crime against the person (e.g., assaults). Drawing on a panel dataset (containing daily and census tract information), we present an analysis employing GIS and robust econometric techniques to show that FCB's matches causally impact crime patterns not just around its stadium, but throughout the city of Barcelona. We also present a spatial analysis of the effect of the club's matches on crime around the stadium by analyzing the extent to which the agglomeration of people impacts each type of crime. To ensure the robustness of our results, we carry out various checks for crime patterns on those days when FCB play away (and when the spatial impacts should not be found). 
The rest of the paper is structured as follows. Section 2 reviews the existing literature that accounts for the potential effects of football on crime. Section 3 presents the datasets used and the matching process applied to the data prior to conducting the empirical estimations. Section 4 presents the methodology for estimating the impact of football matches on crime and the spatial analysis used. Section 5 shows the empirical results from the regression analysis. Section 6 presents the spatial results. Finally, section 7 sums up the paper and concludes.

\section{The multiple effects of football on crime: an examination of the existing literature}

A major sporting event can have a variety of impacts. In the case of football, studies have focused on the effects of a competition such as the FIFA World Cup on employment, tourism, sales, overnight stays (Allmers and Maennig, 2009; Matheson and Baade, 2004; Hagn and Maennig, 2008) and on psychological aspects, such as individual perceptions about economic prospects, both at a personal and economy-wide level (Dohmen et al., 2006; Süssmuth et al., 2010). Additionally, there is evidence of the effect of football on illegal behaviors. Kurland et al. (2014) study the effect of football matches on crime and examine whether football matches in UK (around Wembley Stadium) act as crime generators or crime attractors. ${ }^{5}$ The authors, using an ecological approach to crime (focusing on patterns in space and time) found that, indeed, when Wembley stadium is used there is a significant increase of crime in the area that surrounds it. In a similar vein, although using aggregate Italian province level data, Campaniello (2011) found a significant increase in crime (mainly property crimes) in those provinces that held the 1990 Football World Cup matches. Also analyzing the FIFA world cup tournament Kirby et al. (2013) show how football matches were associated with an increase in domestic violence in the United Kingdom.

Marie $(2011,2016)$ describes three main channels through which football matches may affect crime. ${ }^{6}$ First, the concentration effect is the most straightforward of the effects to be

\footnotetext{
${ }^{5}$ See the crime pattern theory (Brantingham and Brantingham, 1993) for a detailed explanation of offense patterns and the dynamics involved; and see Brantingham and Brantingham (1995) for an explanation of their classification of places as crime generators or crime attractors. In a nutshell, given the importance of places in the crime pattern theory football matches can be seen as both a crime attractor (they draw intending offenders because of known suitable targets) and as a crime generator (offenders are part of the population that frequent the match and take advantage of the unanticipated opportunities encountered).

${ }^{6}$ Spectator violence in stadiums has been a longstanding tradition and, as pointed out by Madensen and Eck (2008), documentation of such events is found in texts from ancient Greece and the Roman Empire. See Madensen and Eck (2008), and references therein, for a complete guide to address the problem of spectator violence in stadiums and other arena-type settings, discussing the factors that contribute to such incidents and reviewing the responses to the problem, and what is known about them from evaluative research and police practice.
} 
considered. Simply put, an agglomeration of individuals in a particular place is likely to increase social interactions, which combined with high levels of alcohol intake may lead to interpersonal violence (clashes and fighting often referred as hooliganism) and property crimes (especially, theft and pick pocketing). ${ }^{7}$ In accordance with routine activity theory (Cohen and Felson, 1979), for a crime to occur, a suitable target, a motivated offender and the absence of a capable guardian must converge in time and space. A football match increases exponentially the number of potential targets, which in turn attract a certain number of motivated offenders (above all pick pockets given that the rewards should be high), while the agglomeration itself reduces the probability of apprehension (anonymity). If these elements all converge, then we would expect to observe an increase in the number of property crimes around a football stadium on match days (a hypothesis that we aim to test in our empirical exercise).

Agglomerations, albeit at a smaller scale, may also occur in other parts of the city (and not only in the vicinity of the stadium), since supporters and football fans often gather in public places to watch the match or to celebrate (lament) a victory (a defeat). Therefore, a rise in thefts might be expected in other areas of the city on a match day. Additionally, when the team is playing away, while an impact around the stadium would not be expected, we might expect to see some effects in those places where matches can be watched (pubs and bars, etc.); and this hypothesis will also be tested.

Second, the profiles (gender and age) of the average football fan and potential offender are not dissimilar, which may have a number of implications for crime rates. Specifically, our crime dataset including known offenders in Barcelona between 2007 and 2011 reveals that $79 \%$ were male; $76 \%$ were under the age of 40 ; and, $63 \%$ were under the age of 35 , a profile that is, in general, very similar to that of football fans, as in the case of London, as captured by the FA Premier League Fan Survey 1994-1997. The coincidence of the two profiles might, on the one hand, point toward a potential increase in illegal activities, or, on the other, to a 'self-incapacitation effect', as a share of the population with a similar profile to those presenting a greater propensity to commit illegal activities will always be watching the match, resulting in a fall in the crime rate. ${ }^{8}$

\footnotetext{
${ }^{7}$ Regarding the intimate relation between alcohol intake and sporting events Duncan et al. (2016) provide evidence on how Super Bowl exposure increases the probability of low birth weight, pointing to an increased exposure to alcohol (and tobacco) of parents and friends as a mechanism that, of course, may be also at work in the present paper.

${ }^{8}$ Self-incapacitation due to the attendance of an event by a part of the population with a greater propensity to commit crimes has been examined by Dahl and DellaVigna (2009) in the case of violent blockbuster movies. Here, we expect the incapacitation effect to be manifest during the ninety minutes of the game. However, after
} 
The third effect, also cited in Marie $(2011,2016)$, is that of 'displacement', given the reassignment of police officers to points around the stadium on match days. ${ }^{9}$ This represents an opportunity for criminals in areas in which levels of surveillance have been relaxed. The spatial analysis we perform here at the city level provides us with some insights as to whether this effect is evident for the city of Barcelona. Note, however, that if the number of police officers assigned to other areas of the city is not reduced on match days, this effect will not exist.

These three channels may not appear to increase crime when the data is examined on a daily basis; only an hourly analysis can reveal their presence. For instance, Montolio and Planells-Struse (2016) detect the incapacitation effect only during the football match itself, while the same authors report a substitution (displacement) effect with police officers apparently being reassigned from certain activities (driving- and drug-related offenses) to others in which their primary concern is guaranteeing citizen security and maintaining traffic flow.

Regarding the specific problem of hooliganism, and although our aim is not to unveil its determinants, there is a vast sociological, psychological and even anthropological literature analyzing such phenomenon. ${ }^{10}$ In the economics literature the evidence is scarcer. Priks (2010) empirically tests the frustration-aggression hypothesis using hooligan data for Sweden, finding that, indeed, frustration (team's bad performance) increases unlawful supporter behavior. In this sense, this evidence points out how frustrated supporters can act violently even if in principle they do not belong to organized radical supporter groups that are those usually identified as hooligans and that they sometimes act more like street gangs being violent at random. ${ }^{11}$ Moreover, Poutvaara and Priks (2009) and DiDomizio and Caruso (2014) present evidence of the impact of counter-hooliganism policies in Sweden and Italy, respectively.

the final whistle, crime may increase as a result of both the incapacitation effect being lifted and the outcome of the match (see Montolio and Planells-Struse, 2016).

${ }^{9}$ In general terms, we understand spatial displacement to occur when offenders switch from targets in one location to those in another. As opposed to temporal, target tactical, offense or perpetrator displacement, spatial is by far the most commonly recognized type of displacement in the criminological literature (see, among others, Bowers et al., 2011).

${ }^{10}$ See Russell (2004) for a social-psychological review on sports riots.

${ }^{11}$ Note that in Spain, some members of radical supporters organizations have been linked by police forces with all sort of criminal activities. Examples can be found, among other, for Real Madrid CF radical supporters (Ultra Sur);

http://www.elmundo.es/madrid/2014/12/17/5491f6f7268e3e37598b457e.html?a=8191 dfbf0bfaec17d197d612 32f6a4c2\&t=1418908926 (last accessed October 2017) and for FCB; http://www.elmundo.es/elmundo/2012/09/12/barcelona/1347472104.html (last accessed October 2017). 
The empirical hypotheses we will test in the rest of the paper can be summarized as follows. First, the research hypothesis regarding property crimes is that we expect that both the agglomeration of individuals and the coincidence of the (average) profile of football fans and potential offenders may increase crime rates close to the stadium on match days, but this impact should not be present during away matches in that specific area of the city. Similarly, we also expect an increase in property crimes for the whole city taking into account the fact that people also gather in other parts of the city to follow the football match, an effect that could also be present during away matches. Second, the research hypothesis regarding crimes against the person, that is acts of interpersonal violence not motivated by taking another's belongings, is based on a vast literature on the impact of incidental emotions (emotions individuals carry with them to the decision that have nothing to do with the decision itself such as happiness, fear, and anger) on decision making. ${ }^{12}$ Rossi and Munyo (2013) provide estimates of the effect of incidental emotions of frustration and euphoria on decision making, in particular on the decision to engage in violent crime. We expect the incidental emotions, exacerbated by the football atmosphere, to lead individuals towards involvement in more violent behaviors resulting in violent crimes (see also Card and Dahl, 2011 for the impact on family violence and the emotional cues associated with wins and losses by professional football teams in the US). ${ }^{13}$ We expect this impact to be more pronounced closer to the stadium where the increase in social interactions caused by the concentration of individuals (in a specific place at a specific time) can easily be the spark that ignites tempers.

The study reported in this paper - combining regression and spatial analyses - seeks to provide a precise characterization of the spatio-temporal patterns of crime and football in the city of Barcelona and aims at helping policy makers in their efforts to reduce sport-related illegal behaviors.

\footnotetext{
${ }^{12}$ Note that incidental emotions appear in very different situations that are not directly related to sports and, hence, our results can extend the literature relating emotions and individual behavior (see for instance Vohs et al., 2007).

${ }^{13}$ The theoretical background for linking gender violence and the emotional cues associated with wins and losses in sports was provided by Card and Dahl (2011) who hypothesized that family violence can be understood as the result of a gain-loss utility of game outcomes around a rationally expected reference point; see also Eren and Ozcan (2017), and references therein, for the impact of unexpected sports results (US college football) on behavioral responses of judges. Although this rationale could be in principle applied to our paper (at least for the case of assaults that involve some sort of violence), the empirical translation needs some refinements given that our set up does not completely fit that framework given the nature of the football team (FCB) we analyze. In this sense, we only analyze the results of one specific team; the betting market in Spain is not as developed as in other countries such as US or UK; and we expect that, by default, FCB is always considered as favorite to win each and every game, hence, with low pregame point spread.
} 


\section{Data}

\subsection{Crime data}

We use a non-public dataset for the city of Barcelona containing all crimes registered by the autonomous police agency in Catalonia (the Spanish region in which Barcelona is located), the Mossos d'Esquadra, which is responsible for crime prevention, crime solving and specialized crime investigation in the Catalan region. ${ }^{14}$ The dataset holds reports filed by both citizens and the Mossos d'Esquadra, as well as by the local police (the Guardia Urbana), responsible primarily for urban traffic and upholding municipal laws and ordinances.

The dataset records the time of the crime (when known), the location and the crime type. The dataset, which extends from 1 September 2007 to 31 December $2011,{ }^{15}$ was restricted so as to include only those months that correspond to the official football season (i.e., June, July and August have been removed). Of the remaining 635,065 observations, 98.74\% (627,037 observations) were geocoded with a precision of within ten meters. ${ }^{16}$

Illegal activities were classified in accordance with the roughly 190 articles of the Spanish penal code. However, to reduce the number of categories without causing an aggregation bias that might reduce the effectiveness of our estimations (Cherry and List, 2002), we combined some of these articles, paying particular attention not to aggregate crimes with different offender motivations. For the main property crimes, we used the variable "Thefts", i.e., the misappropriation of the belongings of others, while for the main crimes involving interpersonal violence, we included the variable "Assaults", i.e., harmful, offensive contact perhaps resulting in injuries (which can be associated with hooliganism). Note that robberies are not omitted from the analysis (they represent $5 \%$ of all crimes in our temporal sample) and are indeed accounted for within the variable Thefts. The main reason is that both robberies and thefts have basically the same motive, that is, the misappropriation of the belongings of others against their will (with and without violence, respectively). For the purposes of crime reporting, if the offender is carrying a weapon (usually a knife) or if the offender pushes away a victim when escaping from the crime scene then the illegal behavior can be considered to involve violence (robbery instead of theft). However, this is a type of

\footnotetext{
${ }^{14}$ The Mossos d'Esquadra are responsible for virtually all police duties. The Spanish National Police (Cuerpo Nacional de Policía) and the military police (Guardia Civil) retain a number of administrative responsibilities (e.g., issuing of identity cards and passports) and undertake counter-terrorist and anti-mafia activities.

15 The original dataset contained a total of 978,218 observations; with 953,257 observations that could be properly geocoded.

${ }^{16}$ The data coordinate type was UTM-31N, based on the European Datum 50 (ED 50) projection, although, for the sake of homogeneity with other layers of polygons, we re-projected the coordinates to ETRS89. The geocoding process was undertaken, in part, by the Mossos d'Esquadra, and completed using GIS techniques, with some 40,000 observations being geocoded by hand using Google Maps.
} 
violence that we want to distinguish from the possible violence provoked by a hooligan just "for fun", induced by football rivalry or exaltation, or by the use and abuse of alcohol and drugs related precisely with the football match. The latter violence is more related with interpersonal violence between aggressor and victim for other motives that are not related with the (economic) reward of the illegal action. ${ }^{17}$

Thefts and Assaults, as defined above, account for nearly the $70 \%$ of all crimes that occurred in Barcelona in our period of study. However, as a robustness exercise, we report in Appendix $\mathrm{C}$ the main results for a type of crime that we believe is, in principle, unrelated to football matches, Fraud, which accounts for $3.7 \%$ of all recorded crimes. In principle, we do not expect to find any significant impact of football matches on fraud counts. ${ }^{18}$

After eliminating all observations responding to other crime types, the final data subset comprised 359,711 geocoded observations. We aggregated all the crime data up to the census tract level. The city of Barcelona is made up of ten districts divided into 73 neighborhoods, which are in turn broken down into 1,061 census tracts according to the electoral population. ${ }^{19}$ We opted to use this unit of analysis as it is the smallest available and, moreover, it can be directly linked to the districts, which are the primary spatial units employed by the police for their policing and strategy decisions. Additionally, as the census tracts are determined according to the population, we indirectly control for the population at risk in each spatial unit.

\subsection{Football data}

We merged the above crime dataset with that for the football matches played by FCB between 1 September 2007 and 31 December 2011 (again excluding the months of June, July and August).

This data set contains information about the day, time, result, number of spectators and the location of the match (i.e., played either at home or away). Table 1 reports the number of matches played and the corresponding attendance figures. The level of attendance was high

\footnotetext{
${ }^{17}$ We have performed the main estimations of the paper (not reported but available upon request) treating robberies as a form of violence and, hence, including them in the variable Assaults, obtaining coherent results with those presented in the rest of the paper.

18 The variable Fraud is defined as the sum of complaints filed regarding alteration of prices, scams, counterfeiting documents, money laundering, usurpation of civil status, fraud, fraudulent use of the electricity supply, defrauding the public sector, crimes against industrial property, crimes against intellectual property, corporate crime, disclosure of secrets, bank fraud (misuse of credit cards), computer scams, counterfeiting a public document, currency or stamps, forgery, punishable insolvency, embezzlement, undertaking activities without insurance and use of false identification.

${ }^{19}$ We use the census tracts for the 2011 municipal elections. One advantage of this spatial division is its homogeneity, with each containing a minimum of 500 and a maximum of 2,000 citizens.
} 
for home matches with $75 \%$ being watched by more than 60,000 spectators and just seven being attended by fewer than 40,000 spectators. $^{20}$

Table 1. FC Barcelona football matches 2007 - 2011.

\begin{tabular}{|lc|}
\hline Attendance & \# of matches \\
\hline$>80,000$ spectators & 36 \\
$>40,000$ and $<80,000$ spectators & 58 \\
$<40,000$ spectators & 24 \\
\hline Total number of home matches & 7 \\
Total number of away matches & 125 \\
\hline Type of match & 130 \\
\hline Domestic League & 169 \\
King's Cup & 32 \\
European Champions League & 50 \\
Spanish and International Super Cup & 4 \\
\hline
\end{tabular}

Note: In this period FC Barcelona played Real Madrid CF, their main rival, ten times (home and away). Source: own elaboration.

The dataset consists of a total of 125 home and 130 away matches. The majority of matches were played in the Spanish domestic league (169), followed by the King's Cup (32 matches played); however, the European Champions League matches (a total of 50) attracted by far the highest gates. Of the 255 matches, ten were played against the historic rival, Real Madrid CF, the majority being Spanish domestic league games.

\subsection{Control variables}

We added a number of variables to control for weather conditions to both datasets. These included rainfall per day, the number of sun hours per day, the average temperature per day, the average daily atmospheric pressure and the average daily wind speed. All these weather factors have been shown to be good explanatory variables for crime (Anderson, 2001; Jacob et al., 2004). For instance, rainfall can reduce the potential number of targets in the streets as people prefer to stay at home, while the number of sun hours and higher temperatures can

${ }^{20}$ FC Barcelona's stadium, the Camp Nou, is the fifth largest football stadium in the world with a capacity, at February 2013, of 99,354 spectators. 
increase this number as people take to the streets and so the potential number of thefts also rises. $^{21}$

Table 2. Descriptive statistics for the whole city of Barcelona.

\begin{tabular}{|c|c|c|c|c|}
\hline & Mean & Std. Deviation & Min. & Max. \\
\hline \multicolumn{5}{|c|}{ Home match days } \\
\hline \multicolumn{5}{|c|}{ Crime variables } \\
\hline Thefts & $\begin{array}{c}377.72 * * * \\
(0.000)\end{array}$ & 63.37 & 252 & 558 \\
\hline Assaults & $\begin{array}{c}21.95 \\
(0.585)\end{array}$ & 5.32 & 13 & 36 \\
\hline \multicolumn{5}{|c|}{ Control variables } \\
\hline Rainfall & $\begin{array}{c}1.13 \\
(0.135)\end{array}$ & 2.84 & 0 & 14.1 \\
\hline Sun hours & $\begin{array}{c}6.34 \\
(0.580)\end{array}$ & 3.68 & 0 & 12.7 \\
\hline Temperature & $\begin{array}{c}13.02 \\
(0.779)\end{array}$ & 4.72 & 2.7 & 25.5 \\
\hline Pressure & $\begin{array}{l}959.40 \\
(0.455)\end{array}$ & 86.79 & 0 & 981.35 \\
\hline Wind Speed & $\begin{array}{c}14.81 \\
(0.580)\end{array}$ & 5.91 & 2.88 & 36 \\
\hline \multicolumn{5}{|c|}{ Away match days } \\
\hline \multicolumn{5}{|c|}{ Crime variables } \\
\hline Thefts & $\begin{array}{c}373.27 * * * \\
(0.009)\end{array}$ & 65.37 & 172 & 524 \\
\hline Assaults & $\begin{array}{c}23.22 * * * \\
(0.002)\end{array}$ & 6.96 & 9 & 48 \\
\hline \multicolumn{5}{|c|}{ Control variables } \\
\hline Rainfall & $\begin{array}{c}1.39 \\
(0.280)\end{array}$ & 5.57 & 0 & 43.6 \\
\hline Sun hours & $\begin{array}{l}7.307 * * \\
(0.011)\end{array}$ & 3.64 & 0 & 13.3 \\
\hline Temperature & $\begin{array}{c}12.96 \\
(0.676)\end{array}$ & 5.32 & 0 & 25.9 \\
\hline Pressure & $\begin{array}{l}960.23 \\
(0.398)\end{array}$ & 85.16 & 0 & 982.8 \\
\hline Wind Speed & $\begin{array}{c}14.30 \\
(0.375)\end{array}$ & 5.60 & 2.88 & 36 \\
\hline
\end{tabular}

Note: crime variables report crime counts. In brackets we report $p$-values from a $t$-test comparing days with home and away matches (respectively) with non-football days. Source: Mossos d'Esquadra and own elaborations.

Table 2 shows the main descriptive statistics for the days with home matches and the days with away matches. It is evident that the statistics for the weather related variables are similar in the case of match days (home and away) when compared with the rest of the days. In other words 'football days' are similar to 'non-football days' in terms of temperature, number of sun hours, atmospheric pressure and wind speed. As for the main dependent variables, the

\footnotetext{
${ }^{21}$ Weather variables are exogenous to crime and they are not correlated with match days (either home or away), although they can affect (home) match attendance. Therefore, controlling for such variables it is important to increase precision of the estimated effects of football matches on crime.
} 
number of thefts, mainly pick pocketing, is higher on days when FCB were playing both at home and away, although when the match was at home the difference was greater. In contrast, in the case of assaults, no difference is observed between the number of assaults committed on home match days with respect to other days; however the number of assaults is higher during away match days when compared with the rest of the days.

\section{Empirical approach: effects of football matches on crime}

\subsection{Regression approach}

In order to estimate the overall effect of football matches on crime for the city of Barcelona, we omit, for the time being, the spatial variation of crime. In other words, we use the two datasets presented above with the crime counts by typology and the day of the year. We estimate a model of the following form:

$$
\text { Crime }_{t}^{m}=\beta_{1} \text { Home_Match }_{t}+\beta_{2} \text { Away_Match }+\beta_{3} X_{t}+\varepsilon_{t}
$$

where $t$ represents the date and $m$ the type of crime (theft or assault). Hence, Crime ${ }_{t}{ }_{t}$ represents the number of crimes of type $m$ each day $t$.Home_Match $h_{t}$ is the variable capturing the fact of FCB playing at home or not. This variable takes different forms, including dummies for home match days and different dummies to account for the level of attendance. Likewise, when FCB play away, we include the variable Away_Match in Eq. (1), which takes a value of 1 when FCB play away and 0 otherwise. Note that it is important to control for both, home and away matches in the same regression, otherwise the model would confound the effect of no match with an away match, given that both would be coded as being zero and, of course, an FCB away match could be also affecting crime.

$X$ is a vector containing potential predictors of thefts and assaults including averages of rainfall, number of sun hours, temperature, atmospheric pressure and wind speed as presented above. Moreover the vector $X$ contains time fixed effects to capture any potential heterogeneity across days, months or years. Specifically, it contains a holiday fixed effect to account for specific dates across the year. ${ }^{22} \mathrm{We}$ also include a day of the week fixed effect (a fixed effect for the seven week days from Monday to Sunday) to capture the heterogeneity of crime counts across days of the week. In this sense, weekly crime patterns seem to increase from Wednesday to Sunday, with a marked weekend effect. Additionally, to account for

\footnotetext{
22 The holiday fixed effect refer to special days during the year that are holidays in Spain, Catalonia or Barcelona, such as 01-Jan; 06-Jan; 01-May; 24-Jun; 15-Aug; 11-Sept; 12-Oct; 6-Dec; 8-Dec; 25-Dec; 26-Dec.
} 
heterogeneity across weeks and months, we introduce a week and month fixed effect. ${ }^{23} \mathrm{We}$ also include a year fixed effect to reflect the differences in crime across the five years of our data span and a season fixed effect to account for seasonal variations in crime.

Furthermore, also in the vector $X$ in Eq. (1) we include a set of variables related to the football match being played. Specifically, it consists of dummy variables for the competitions being played and a dummy variable for special matches, such as those played between FCB and Real Madrid CF. Finally, $\varepsilon_{t}$ represents the error term, which is assumed to be normally distributed with constant variance.

In order to estimate Eq. (1), we employ a basic Ordinary Least Squares (OLS) estimation with all the control variables presented above that account for variations in crime over time. Given the time series context of Eq. (1) we use the corrected for first-order serially-correlated residuals using the Prais-Winsten transformed regression estimator to account for any potential serial correlation problem arising from the errors.

As a robustness test we regress Eq. (1) also adding a dummy variable that takes value 1 for days following a match day, also distinguishing between home and away matches, and 0 otherwise. ${ }^{24}$ This robustness exercise is carried out since the effect of football matches on crime may persist during the following day after the match as shown in Montolio and Planells-Struse (2016). The authors find that some types of crime, such as thefts, are significantly more frequent even eight hours after the football match. Given that on average, the typical kick off and final whistle times for FCB football matches are between 20:00 and 22:00 the effect of the football matches on crime could be recorded the next day.

\subsection{Spatial approach}

After estimating the overall effects of football matches on crime, we are interested in analyzing changes in its spatial distribution when FCB play at home and away (treatment) and in comparing these outcomes with 'non-football days' (control). To do so, we undertake an Exploratory Spatial Data Analysis (ESDA, hereafter), which allows us to determine the presence of "hot spots" (areas where crime is more spatially concentrated) in the city of Barcelona employing kernel density functions and average nearest-neighbor statistics (Chainey et al., 2008). ${ }^{25}$ Additionally, we carry out a confirmatory analysis by means of

\footnotetext{
${ }^{23}$ Note that there are some weeks that do belong to different months so there is not perfect collinearity between the week and the month indicator.

${ }^{24}$ The results from this robustness exercise can be found in Appendix A.

${ }^{25}$ Using Local Indicators of Spatial Autocorrelation (LISA) would be a very useful tool to identify those census tracts with high/low values of crime surrounded by other census tracts also with high/low values of crime. However, in the case of Barcelona, its city center distorts the analysis if this technique is applied. Focusing only
} 
regressing crime occurrence as a function of a distance to the FCB stadium. More specifically, we carry out the following Differences-in-Differences regression:

$$
\begin{aligned}
& \text { Crime }_{i t}^{m}=\sum_{k=300}^{1400} \xi_{k} \text { dist }_{i k}+\sum_{k=300}^{1400} \eta_{k} \text { dist }_{i k} \text { Home_Match }_{t}+\sum_{k=300}^{1400} \theta_{k} \text { dist }_{i k} \text { Away_Match }_{t}+ \\
&+\beta_{1} \text { Home_Match } \\
& t
\end{aligned}
$$

where $i$ denotes the census tract, $\sigma$ denotes a vector containing census tracts fixed effects, and all the other variables and parameters are as in Eq. (1) except for three new parameters and variables. The first of these, $\sum_{k=300}^{1400} \xi_{k} d_{i s t_{i k}}$, is a set of dummy variables that takes a value of 1 if the centroid of census tract $i$ is within distance $k$ (in meters) of the FCB stadium and 0 otherwise. This set of dummies captures the impact on crime of being within a certain distance of the stadium both on 'football days' and 'non-football days'. The other two are $\sum_{k=300}^{1400} \eta_{k}$ dist $_{i k}$ Home_Match $_{t}$ and $\sum_{k=300}^{1400} \theta_{k}$ dist $_{i k}$ Away_Match $_{t}$, that represent the interactions term of the previous distance variable and the dummies indicating a match day (home or away). As such, the parameters $\eta_{k}$ and $\theta_{k}$ capture the effect of being within a certain distance of the stadium when a football match is being held (at the stadium or away). Clearly, during home games, we expect the number of crimes to rise as we get closer to the stadium, in part, due to the greater number of social interactions between supporters and, in part, due to the concentration effect that attracts offenders to crowded areas around a stadium. We adopt a non-cumulative rings approach to capture the distance decay effect. In other words, we focus on the way in which crime counts vary between census tracts at distance $k$ and $k$-100 (in meters). We expect a distance decay pattern, as individuals are likely to be more spread out the further we move away from the stadium. Note that with respect to away matches we do not expect such results.

With the inclusion of this new dimension (the census tracts), the non-trivial number of zeros and the positive skewed distribution of the crime counts, makes non-linear estimators more suitable. Moreover, the data present a problem of over-dispersion. In other words, the variance of the crime counts (both thefts and assaults) is larger than their mean. Therefore,

on the close surroundings of the FCB stadium reduces the number of spatial units and, hence, the use of LISA technique is not a plausible solution since it is not recommended for datasets with a low number of spatial units (Anselin, 1995). 
we use a negative binomial approach that takes into account all the characteristics that differ from the standard assumptions underlying the OLS estimation. ${ }^{26,27}$

\section{Regression results}

Table 3 shows the results of estimation Eq. (1), that is, it shows the average effect of a football match being played at home on theft and assault counts. The first column represents a simple correlation with no control variables. Column 2 includes all time fixed effects except for the year fixed effects. Column 3 includes also the weather control variables. Finally, in column 4 we include the year fixed effects. The estimated coefficients in column 4 show that, on average, there are close to 12 thefts more on those days when FCB play at home. In the case of assaults, there is no significant increase in the number of assaults committed in the city of Barcelona. As expected, there seems not to be any impact when FCB plays away. Results in Table 3 show we are able to explain approximately $63 \%$ of the variation of thefts across the city of Barcelona. The average number of assaults (given by the constant) is much lower than the average number of thefts and, also, compared to the theft regressions, the models for assaults are only able to explain, as expected, around $22 \%$ of the variance in the number of assaults.

It might be the case that only matches with a certain attendance (importance) affect crime. The variance in the number of spectators might affect the way in which potential offenders perceive their opportunities for committing crimes and their potential rewards. Yet, if police deployment is greater during "hot" matches (with high attendance), pickpockets may decide that their activities are only worthwhile on match days when police deployment is less intense. In the case of assaults, "hot" football matches may increase the number of potentially violent supporters or hooligans.

In order to account for the effect of the number of spectators, Table 4 includes dummy variables that takes a value of 1 if the home match is played before more than 60,000 spectators (Home_large_crowd); before a crowd between 40,000 and 60,000 spectators

\footnotetext{
${ }^{26}$ Notice that in our setting the large mass at zero does not call for a zero-inflated modelling strategy. The basic assumption behind such strategies is that an "excess" mass of zero-outcomes is produced due to the fact that part of the population (census tracts) does not actually participate in the count-generating process, that is, for that part of the population there is no chance to observe any outcome but zero. In our case of crime rates, we do not have any reasons to exclude, a priori, that any specific census tract-day combination may produce a positive count of criminal actions.

${ }^{27}$ Note that given that we estimate a negative binomial model, the coefficients reported in the corresponding tables are the incidence rate ratios that represent the increase (above 1) or decrease (below 1) in percentage of the number of counts of each crime type. Moreover, the fact of reporting incidence rate ratios renders the standard errors useless, since they cannot be compared to a point estimate. Accordingly, we report $p$-values in the tables presenting the negative binomial results.
} 
(Home_medium_crowd); and before less than 40,000 spectators (Home_small_crowd). Regarding away attendance we use the opponents' stadium capacity where FCB plays away. Note that the visit of FCB usually fills up stadiums and we are confident that in away matches stadiums are close to full capacity.

Table 3. OLS estimations. Effect of matches played at home and away on theft and assault counts.

\begin{tabular}{lccc}
\hline VARIABLES & $(1)$ & $(2)$ & $(3)$ \\
\hline & Thefts & Thefts & Thefts \\
Home Match & 12.43 & 10.33 & $12.01^{*}$ \\
& $(7.605)$ & $(7.428)$ & $(7.163)$ \\
Away Macth & 1.693 & -2.752 & -1.418 \\
& $(6.215)$ & $(6.089)$ & $(5.763)$ \\
Constant & $467.6^{* * *}$ & $443.1^{* * *}$ & $418.8^{* * *}$ \\
& $(22.22)$ & $(21.55)$ & $(18.51)$ \\
t-test $\beta^{\text {Home }}=\beta^{\text {Away }}$ & $6.07^{* * *}$ & $9.55^{* * *}$ & $10.40^{* * *}$ \\
& {$[0.013]$} & {$[0.002]$} & {$[0.001]$} \\
$R$-squared & 0.544 & 0.583 & 0.635 \\
Durbin-Watson (original) & 1.25 & 1.24 & 1.51 \\
Durbin-Watson (transformed) & 2.02 & 2.04 & 1.97 \\
\hline & Assaults & Assaults & Assaults \\
Home Match & -3.558 & -3.365 & -3.677 \\
& $(3.242)$ & $(2.992)$ & $(2.908)$ \\
Away Match & -2.295 & -2.214 & -2.522 \\
& $(3.152)$ & $(2.894)$ & $(2.816)$ \\
Constant & $26.78^{* * *}$ & $25.21^{* * *}$ & $25.73^{* * *}$ \\
& $(1.958)$ & $(2.115)$ & $(2.209)$ \\
t-test $\beta^{\text {Home }}=\beta^{\text {Away }}$ & $2.84^{*}$ & 2.38 & 2.39 \\
$R$-squared & {$[0.092]$} & {$[0.123]$} & {$[0.122]$} \\
Durbin-Watson (original) & 0.196 & 0.220 & 0.226 \\
Durbin-Watson (transformed) & 1.97 & 1.99 & 2.00 \\
\hline Observations & 1.98 & 1.98 & 1.98 \\
Climate controls & 1,215 & 1,215 & 1,215 \\
Time controls & NO & YES & YES \\
Year fixed effects & YES & YES & YES \\
Seasonal controls & NO & NO & YES \\
Derby dummy & YES & YES & YES \\
No OS & YES & YES & YES \\
\hline
\end{tabular}

Notes: OLS results of estimating Eq. (1) using the corrected for first-order serially-correlated residuals using the PraisWinsten transformed regression estimator. Dependent variable crime counts. Climate controls include: average rainfall, average number of sun hours, average temperature, average pressure and average wind speed. Time controls include: day of the week, holiday indicator, week of the year, weekend and month. Seasonal controls include dummies for summer (mainly September) and winter. Robust standard errors are shown in parentheses. p-values in square brackets. $* * * \mathrm{p}<0.01$, $* * \mathrm{p}<0.05, * \mathrm{p}<0.1$.

Table 4 shows the impact of football matches on theft counts taking into account the importance of the match played. The four columns represent the same estimated model as in Table 3 above. In column 4, the most complete model, the estimated coefficients identify an increase of almost 15 thefts on important games (more than 60,000 spectators). In the case of assaults, the city of Barcelona does not seem to suffer, on average, a significant impact on the number of assaults. 
Table 4. OLS estimations. Effect of number of spectators on theft and assault counts.

\begin{tabular}{|c|c|c|c|}
\hline VARIABLES & (1) & (2) & (3) \\
\hline & Thefts & Thefts & Thefts \\
\hline \multirow[t]{2}{*}{ Home_small_crowd } & 6.560 & 3.069 & 3.003 \\
\hline & (18.64) & $(18.34)$ & $(15.87)$ \\
\hline \multirow[t]{2}{*}{ Home_medium_crowd } & -4.366 & -5.485 & -5.717 \\
\hline & $(9.779)$ & $(9.447)$ & $(8.795)$ \\
\hline \multirow[t]{2}{*}{ Home_large_crowd } & $15.66^{*}$ & $14.05^{*}$ & $15.09^{*}$ \\
\hline & $(8.586)$ & $(8.388)$ & $(7.780)$ \\
\hline \multirow[t]{2}{*}{ Away_small_crowd } & -2.684 & -4.792 & -5.003 \\
\hline & $(7.684)$ & (7.497) & $(6.864)$ \\
\hline \multirow[t]{2}{*}{ Away_medium_crowd } & 3.936 & -2.438 & -2.263 \\
\hline & $(9.401)$ & $(8.929)$ & $(8.186)$ \\
\hline \multirow[t]{2}{*}{ Away_large_crowd } & 6.254 & -0.444 & 2.528 \\
\hline & $(8.293)$ & $(8.093)$ & $(7.420)$ \\
\hline \multirow[t]{2}{*}{ Constant } & $467.6 * * *$ & $442.5 * * *$ & $418.0^{* * *}$ \\
\hline & $(22.43)$ & $(21.65)$ & $(18.53)$ \\
\hline \multirow[t]{2}{*}{$\mathrm{t}$-test $\beta^{\text {Home_small }}=\beta^{\text {Away_small }}$} & 0.28 & 0.21 & 0.30 \\
\hline & {$[0.595]$} & {$[0.645]$} & {$[0.586]$} \\
\hline \multirow[t]{2}{*}{$\mathrm{t}$-test $\beta^{\text {Home_medium }}=\beta^{\text {Away_medium }}$} & 1.00 & 0.16 & 0.22 \\
\hline & [0.318] & {$[0.690]$} & {$[0.641]$} \\
\hline \multirow{2}{*}{$\mathrm{t}$-test $\beta^{\text {Home_large }}=\beta^{\text {Away_large }}$} & 1.23 & 2.09 & $2.95 *$ \\
\hline & {$[0.268]$} & {$[0.148]$} & {$[0.08]$} \\
\hline R-squared & 0.547 & 0.585 & 0.637 \\
\hline \multirow{3}{*}{$\begin{array}{l}\text { Durbin-Watson (original) } \\
\text { Durbin-Watson (transformed) }\end{array}$} & 1.26 & 1.25 & 1.51 \\
\hline & 2.02 & 2.04 & 1.97 \\
\hline & Assaults & Assaults & Assaults \\
\hline \multirow[t]{2}{*}{ Home_small_crowd } & -3.160 & -2.540 & -2.786 \\
\hline & $(3.923)$ & $(3.734)$ & $(3.654)$ \\
\hline \multirow[t]{2}{*}{ Home_medium_crowd } & -3.738 & -3.395 & -3.562 \\
\hline & $(3.634)$ & $(3.399)$ & $(3.326)$ \\
\hline \multirow[t]{2}{*}{ Home_large_crowd } & -2.508 & -2.232 & -2.515 \\
\hline & $(3.538)$ & $(3.303)$ & $(3.227)$ \\
\hline \multirow[t]{2}{*}{ Away_small_crowd } & -1.514 & -1.281 & -1.551 \\
\hline & $(3.460)$ & $(3.210)$ & $(3.142)$ \\
\hline \multirow[t]{2}{*}{ Away_medium_crowd } & -0.703 & -0.444 & -0.596 \\
\hline & $(3.718)$ & $(3.494)$ & $(3.427)$ \\
\hline \multirow[t]{2}{*}{ Away_large_crowd } & -3.125 & -3.175 & -3.558 \\
\hline & $(3.589)$ & $(3.384)$ & $(3.312)$ \\
\hline \multirow[t]{2}{*}{ Constant } & $26.87 * * *$ & $25.22 * * *$ & $25.79 * * *$ \\
\hline & $(1.953)$ & $(2.110)$ & $(2.203)$ \\
\hline \multirow[t]{2}{*}{$\mathrm{t}$-test $\beta^{\text {Home_small }}=\beta^{\text {Away_small }}$} & 0.73 & 0.42 & 0.41 \\
\hline & [0.392] & {$[0.518]$} & {$[0.522]$} \\
\hline \multirow{2}{*}{$\mathrm{t}$-test $\beta^{\text {Home_medium }}=\beta^{\text {Away_medium }}$} & $3.65 *$ & $3.53 *$ & $3.57 *$ \\
\hline & {$[0.056]$} & {$[0.060]$} & {$[0.059]$} \\
\hline t-test $\beta^{\text {Home_large }}=\beta^{\text {Away_large }}$ & 0.18 & 0.43 & 0.50 \\
\hline & {$[0.668]$} & {$[0.512]$} & {$[0.479]$} \\
\hline R-squared & 0.17 & 0.222 & 0.228 \\
\hline Durbin-Watson (original) & 1.96 & 1.98 & 2.00 \\
\hline Durbin-Watson (transformed) & 1.98 & 1.98 & 1.98 \\
\hline Observations & 1,215 & 1,215 & 1,215 \\
\hline Climate controls & NO & YES & YES \\
\hline Time controls & YES & YES & YES \\
\hline Year fixed effects & NO & NO & YES \\
\hline Seasonal controls & YES & YES & YES \\
\hline Derby dummy & YES & YES & YES \\
\hline
\end{tabular}

Notes: OLS results of estimating Eq. (1) using the corrected for first-order serially-correlated residuals using the PraisWinsten transformed regression estimator. Dependent variable crime counts. Climate controls include: average rainfall, average number of sun hours, average temperature, average pressure and average wind speed. Time controls include: day of the week, holiday indicator, week of the year, weekend and month. Seasonal controls include dummies for summer (mainly September) and winter. Robust standard errors are shown in parentheses. p-values in square brackets. $* * * \mathrm{p}<0.01$, $* * \mathrm{p}<0.05, * \mathrm{p}<0.1$. 
If we compare our results with respect to the overall population of Barcelona, our results are remarkable. Using data for 2011 when Barcelona had 1,615,448 inhabitants, and given our estimates (that show an average of 418 thefts per day, see the last column in Table 4) the average rate of theft per 10,000 inhabitants in Barcelona per day was 2.58; therefore, the probability of suffering a crime for big matches was nearly 2.5 times larger during football days. Moreover, if these average estimates for the whole city are applied to the District where the FCB Stadium is located (with 82,436 inhabitants in 2011) the increase in the probability of suffering a theft would be obtained if 254,467 persons came to the District from outside Barcelona to be part of the football match (directly at the stadium or indirectly in the vicinities). This number is plausible for a stadium with capacity for 99,354 spectators.

So far we have considered the overall impact of home football matches on theft and assault counts. However, as discussed above, away football matches might also increase criminal activity in the city given that people typically gather in the city's pubs and bars to watch the game. This could generate similar crowding effects that might attract pickpockets or result in outbreaks of violence since alcohol is usually consumed while following the match. Tables 3 and 4 (that include dummy variables for away matches), however, show that neither theft nor assault counts are significantly affected by FCB's away matches. Although the average number of pick pocketing thefts is higher on those days when FCB play away (compared with non-football days), after controlling for weather conditions and time varying variables this increase is not statistically significant. ${ }^{28}$

\section{Spatial results}

\subsection{Exploratory Spatial Data Analysis (ESDA)}

After analyzing the overall effect of home and away football matches on theft and assault counts, we incorporate the spatial dimension by introducing the 1,061 census tracts of the city of Barcelona. We carry out an ESDA analysis to show the main spatial crime patterns on days when FCB play at home and on days when FCB play away (compared both with 'non-football days'). Note that the spatial distribution of crime in the city of Barcelona, from a descriptive point of view, shows that the increase in theft and assault counts in the census tracts located within a certain distance of the stadium represents a sizeable share of the total

\footnotetext{
${ }^{28}$ Table A.1 in appendix A presents the robustness exercise when considering the impacts on the day after the match. The results are very similar to the ones discussed in the main text. In general, the impact of football matches on crime, even if present for some hours after the match that belong to the following day, vanishes given that our time unit is the day and for the whole next day, as expected, we do not find any impact.
} 
increase for the whole city on days when there is a home football match. Specifically, in the case of thefts, the increase in census tracts within a radius of up to 1,200 meters represents $43.59 \%$ of the total increase. In the case of the number of assaults, the census tracts that are located within 1,100 meters of the stadium account for up to $84.21 \%$ of the total increase in the number of assaults across the whole of the city. ${ }^{29}$ This idea of a concentration pattern of thefts and assaults in the census tracts located in the vicinity of the FCB stadium can be depicted in cartographic form.

We show the kernel density estimations in order to identify the places in the city of Barcelona where the risks of being a victim of theft or assault on certain days ('football' and 'non-football') are highest. Kernel density estimations simply provide a smooth estimate of the point process derived by means of a moving window (bandwidth) over the data (Bailey and Gatrell, 1995; Williamson et al., 1998). The estimated kernel values represent the predictive risk surface for each type of crime analyzed, in other words, the potential number of events per square $\mathrm{km}$ when taking into account potential contagious effects from other areas.

Delimiting the area in which to measure the risk of a certain crime, that is, the radius of the circle centered on each grid cell containing the points that contribute to the kernel density calculation, is known as the bandwidth decision problem. Large bandwidths result in over smoothing, with low density values and, therefore, an over generalized view, while small bandwidths result in maps that are spiky in appearance because of the jumps between spatial units (producing images similar to point patterns). Several rules of thumb have been suggested by Williamson et al. (1998) and Bailey and Gatrell (1995) based mainly on the $k$ nearest neighbor mean distances, and dependent on the detail of analysis that the researcher wishes to obtain (city, county, neighborhood, street, parking lot, etc.). However, the bandwidth must also be theoretically justified since it reflects the contagious nature of a particular crime across space. For instance, thefts from vehicles may cluster in a specific parking lot because it has no surveillance cameras. It is reasonable to think that thefts from vehicles are likely to occur in the parking lot with the same degree of probability. If the lot extends over 250 meters, then a 250 - or 300 - meter bandwidth would capture the potential contagious effect. However, choosing a larger bandwidth will have the effect of extending the probability of thefts from vehicles to other areas where no cars are parked. Another

\footnotetext{
${ }^{29}$ These figures are obtained by simply calculating the relative increase in theft and assault counts in census tracts whose centroid is located at a distance of $k$ meters from the center of the FCB stadium relative to the total increase for the whole city of Barcelona.
} 
example would be domestic violence, which tends to be highly focused on specific households. As such, the bandwidth of the kernel density estimation should be very small. In our case, we use a bandwidth of 300 meters for both thefts and assaults. ${ }^{30}$

In Figure 1 the kernel density functions are the result of the difference between the kernel densities for the number of thefts committed on days when FCB play at home (top panel) and away (bottom panel) and those for the thefts committed on 'non-football days' (controls). Similarly, Figure 2 does the same for the case of assaults. The darker areas present the largest increases in the number of thefts and assaults between days when FCB played at home/away and days without football while the white areas present shifts in the other direction.

Figure 1 shows that, in the case of thefts, there is an increase mainly in two areas of the city: first, in the city center where people gather in bars and pubs to watch the match and where victories are celebrated; and, second, in the vicinity of the stadium. A similar pattern is found in Figure 2 for the number of assaults. An increase is observed especially in the city center, but also in areas surrounding the stadium.

Bottom panels of Figures 1 and 2 present "hot spots" corresponding to differences in densities on days when FCB play away and 'non-football days'. Comparing bottom with top panels it is clear that these respective differences (i.e., home matches vs. non-football days and away matches vs. non-football days) do not coincide. On those days when FCB play away, there appear to be increases in theft and assault counts both in the center of the city and in certain areas where pubs and bars concentrate.

In order to focus our analysis on the vicinity of the FCB stadium, Figure D.2 and Figure D.3 in Appendix D show only the crimes committed within a certain distance of the stadium. In this way we are able to understand more fully the fluctuations in crime counts around the football stadium. Figure D.2 shows that the number of thefts increases markedly when FCB play at home (top panel). This is particularly evident in the streets en route to the stadium from the main transport facilities. Figure D.3 shows similar results, although less salient, for the case of assaults. Even though concentrated in smaller areas, there also appears to be a concentration of assaults in the vicinity of the stadium. As expected, neither for thefts nor assaults seems to appear any significant difference between no match day and when FCB plays away around the stadium.

\footnotetext{
${ }^{30}$ Theoretically, the bandwidth for the assaults should be smaller since the contagious effect is lower; however, we opt to use the same bandwidth to make maps comparable.
} 
Figure 1. Difference in kernel density values for thefts between days when FCB play at home (top panel), away (bottom panel) and days with no football.

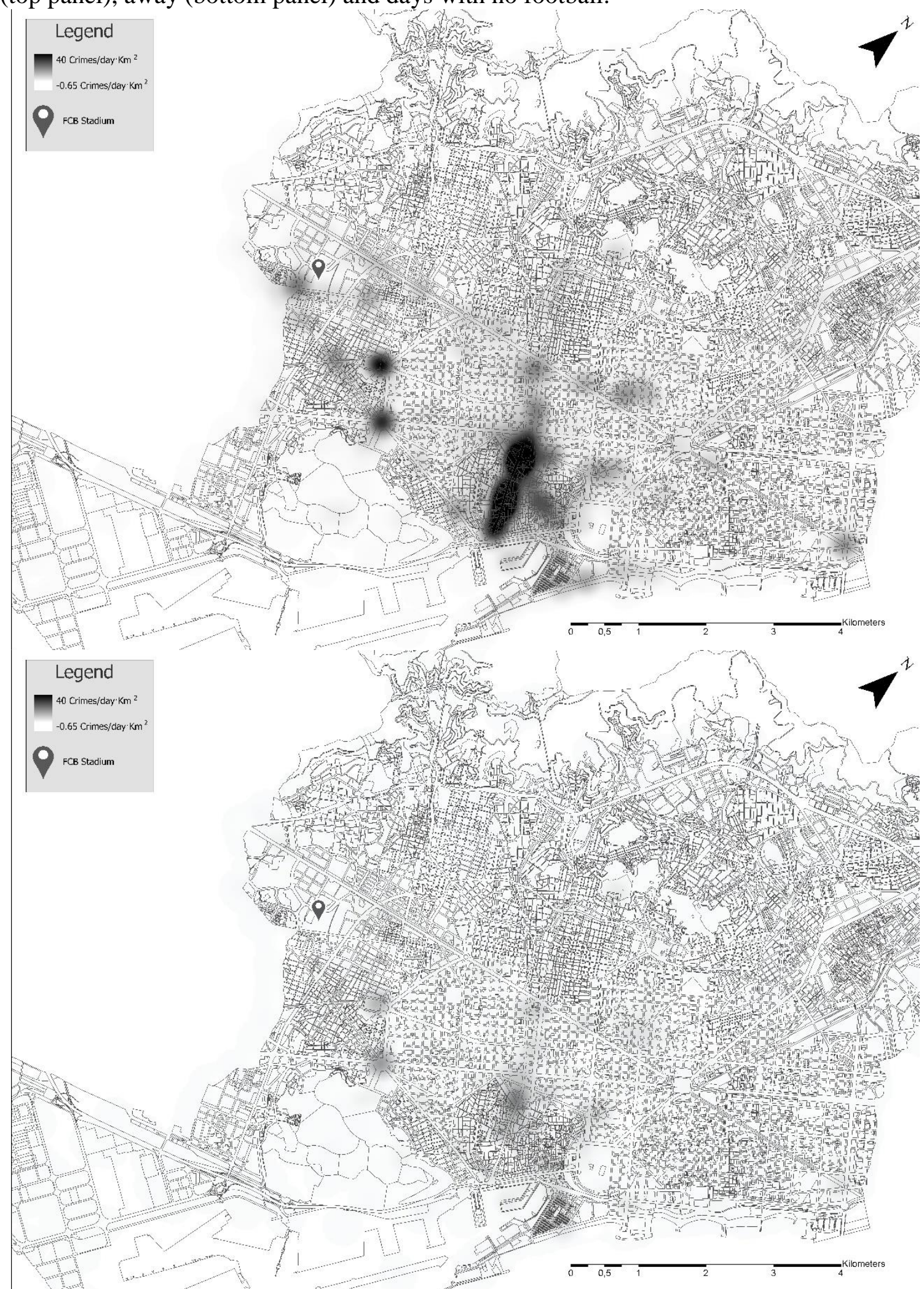

Note: Quadratic kernel functions. The representation is the density function per square km using natural breaks so as to identify outliers clearly. Bandwidths are set at 300 meters for both thefts and assaults. Cell size is set at 20 meters to show as much detail as possible. 
Figure 2. Difference in kernel density values for assaults between days when FCB play at home (top panel), away (bottom panel) and days with no football.

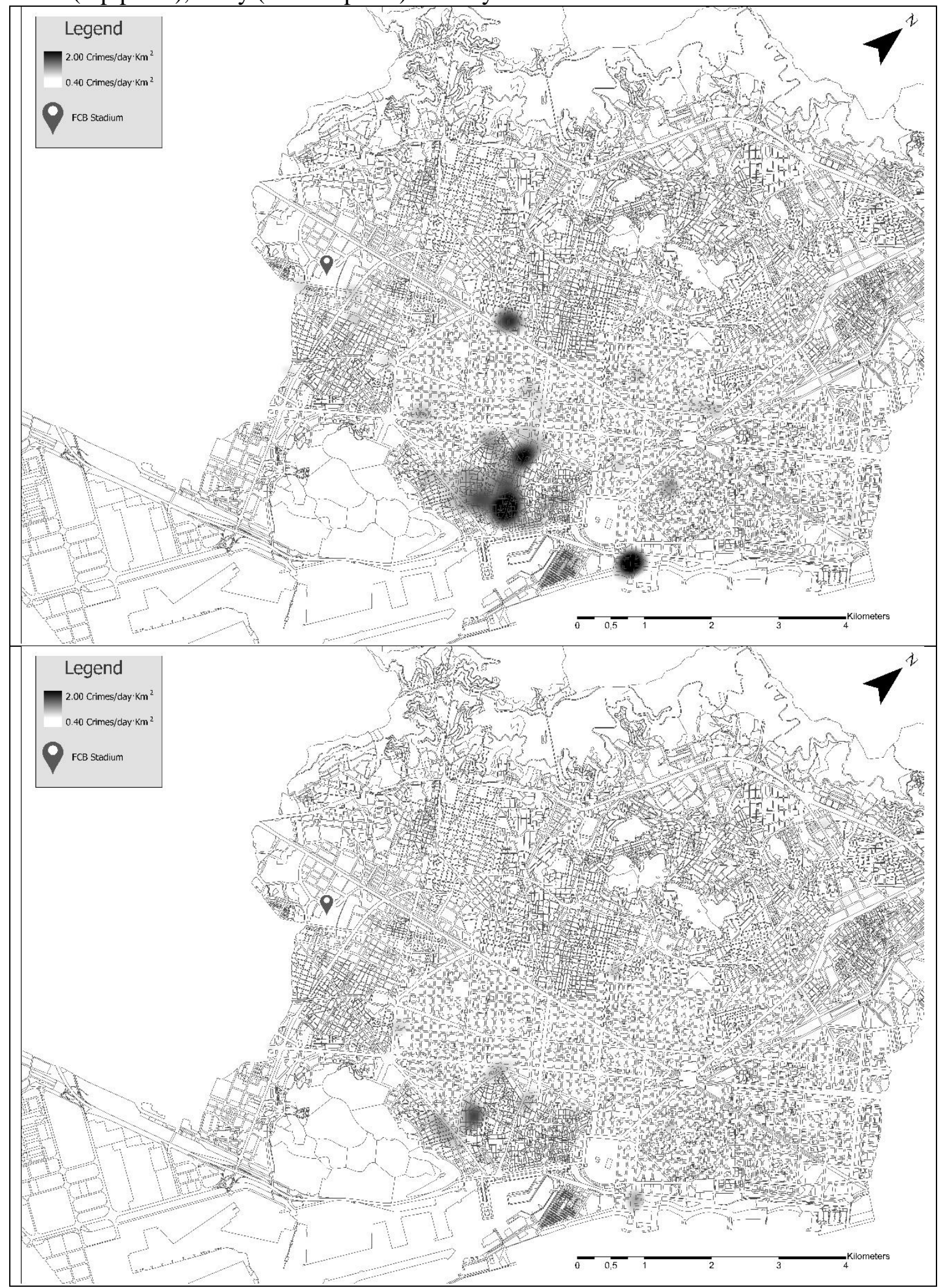

Note: Quadratic kernel functions. The representation is the density function per square km using natural breaks so as to identify outliers clearly. Bandwidths are set at 300 meters for both thefts and assaults. Cell size is set at 20 meters to show as much detail as possible. 


\subsection{Spatial regression approach}

In order to confirm the crime concentration patterns around the FCB stadium when FCB play at home, we estimate the effect of the distance from the stadium on the number of thefts and assaults. We estimate Eq. (2) for both thefts and assaults, using the non-cumulative rings (or buffers). ${ }^{31}$ Table 5 presents the results of our analysis of the effects on thefts counts at specific distances from the stadium, without taking into account census tracts that lie closer to the football ground. Table 6 does the same for the case of assaults. These non-cumulative distance rings show the impact of home football matches in census tracts located 100 meters apart. Figure 3 also reports graphically the estimated coefficients for the non-cumulative rings. $^{32}$

As explained in Section 4.2 we estimate Eq. (2) by means of a negative binomial regression including census tracts fixed effects. As a robustness exercise, we report in Appendix B both OLS estimates (Table B.1) and probit estimates (Table B.2) that results from recoding our dependent variable into a 1/0 variable. Note that the OLS results reported in Appendix B replicate the two preferred specifications; that is, columns (4) and (5) of Table 5 (thefts) and Table 6 (assaults)..$^{33}$

Results show that the number of thefts in the census tracts is negatively affected by the distance to the stadium: the greater the distance, the lower the theft count. This reflects the potential presence of the concentration effect. More precisely, in the case of thefts, the results show a distance decay pattern as we move away from the stadium - being in a census tract whose centroid is less than 300 meters from the stadium when FCB are at home increases the number of thefts by an average of $151 \%$ on the day of a match. The increase in thefts is maximum for census tract whose centroid is between 400 and 600 meters from the stadium (225\% higher probability of suffering a theft). ${ }^{34}$

\footnotetext{
${ }^{31}$ As explained in Section 4.2, each ring represents an increase of 100 meters from the stadium and includes all additional census tracts whose centroid falls within the ring. Figure D.1 maps the rings used, while Table D.1 in Appendix D shows the number of census tracts included in each ring.

${ }^{32}$ As a further robustness exercise, in Appendix E, we provide the graphical results of the estimated coefficients for non-cumulative rings of 150 meters (Figure E.1) and 200 meters (Figure E.2) increase from the stadium.

${ }^{33}$ Reassuringly for us, we obtain very robust results using these alternative econometric specifications with respect to those results obtained using a negative binomial specification.

${ }^{34} \mathrm{We}$ also obtain a distance decay effect if we adopt, as a robustness test, a cumulative rings approach which involves examining the way in which crime counts increase within cumulative rings of distance $k$ (where $k=$ $300,400, \ldots, 1,400$ meters) by regressing Eq. (2) $k$ times with the $k$ distance dummy, since the upper order rings are likely to be correlated to those of a lower order. The results, not reported but available upon request, show an important increase in pick pocketing and assaults during matches in the same census tract as that of the stadium. In general, the results also point out to a clear concentration effect. We also find that these impacts are decreasing (a slower rate) as we move away from the stadium. However, it should be pointed out that the cumulative ring approach is more likely to show the effect of football matches on crime at greater distances
} 
Table 5. Non-cumulative rings. Negative binomial. Thefts.

\begin{tabular}{|c|c|c|c|c|c|}
\hline VARIABLES & $(1)$ & $(2)$ & $(3)$ & $(4)$ & $(5)$ \\
\hline \multirow[t]{2}{*}{ Home_match $<300 m$} & 0.976 & 0.973 & 0.927 & $1.517 *$ & $1.512 *$ \\
\hline & {$[0.0993]$} & {$[0.104]$} & {$[0.114]$} & {$[0.361]$} & {$[0.360]$} \\
\hline \multirow[t]{2}{*}{ Home_match $>300 \&<400 m$} & $2.611 * * *$ & $2.598 * * *$ & $2.482 * * *$ & $1.394 * * *$ & $1.392 * * *$ \\
\hline & {$[0.264]$} & {$[0.273]$} & {$[0.302]$} & {$[0.161]$} & {$[0.161]$} \\
\hline \multirow[t]{2}{*}{ Home_match $>400 \&<500 m$} & 1.747 & 1.744 & 1.658 & $2.137 * * *$ & $2.129 * * *$ \\
\hline & {$[0.629]$} & {$[0.633]$} & [0.627] & {$[0.274]$} & {$[0.273]$} \\
\hline \multirow[t]{2}{*}{ Home_match $>500 \&<600 m$} & $1.143^{* *}$ & $1.140 * *$ & 1.089 & $2.258 * * *$ & $2.251 * * *$ \\
\hline & {$[0.0728]$} & {$[0.0760]$} & {$[0.0955]$} & {$[0.519]$} & {$[0.517]$} \\
\hline \multirow[t]{2}{*}{ Home_match $>600 \&<700 m$} & 1.151 & 1.148 & 1.099 & $1.419^{*}$ & $1.415^{*}$ \\
\hline & {$[0.195]$} & [0.194] & {$[0.173]$} & [0.267] & {$[0.266]$} \\
\hline \multirow[t]{2}{*}{ Home_match $>700 \&<800 m$} & $0.258 * * *$ & $0.257 * * *$ & $0.248 * * *$ & 0.789 & 0.786 \\
\hline & {$[0.0611]$} & {$[0.0616]$} & {$[0.0635]$} & {$[0.213]$} & {$[0.212]$} \\
\hline \multirow[t]{2}{*}{ Home_match $>800 \&<900 m$} & 1.633 & 1.628 & 1.554 & $1.437 * * *$ & $1.432 * * *$ \\
\hline & [1.625] & [1.625] & [1.572] & {$[0.171]$} & {$[0.170]$} \\
\hline \multirow[t]{2}{*}{ Home_match $>900 \&<1,000 m$} & $0.480 * *$ & $0.478^{*}$ & $0.459 * *$ & 0.836 & 0.833 \\
\hline & {$[0.180]$} & {$[0.180]$} & {$[0.177]$} & [0.146] & [0.145] \\
\hline \multirow[t]{2}{*}{ Home_match $>1,000 \&<1,100 m$} & $0.450 * * *$ & $0.448 * * *$ & $0.431 * * *$ & 1.079 & 1.075 \\
\hline & {$[0.106]$} & {$[0.104]$} & {$[0.0952]$} & [0.156] & [0.156] \\
\hline \multirow[t]{2}{*}{ Home_match $>1,100 \&<1,200 m$} & 0.563 & 0.561 & 0.539 & 1.151 & 1.147 \\
\hline & {$[0.374]$} & {$[0.374]$} & {$[0.367]$} & [0.181] & {$[0.180]$} \\
\hline \multirow[t]{2}{*}{ Home_match $>1,200 \&<1,300 m$} & $0.305 * * *$ & $0.304 * * *$ & $0.292 * * *$ & $1.377^{*}$ & $1.372 *$ \\
\hline & {$[0.0471]$} & {$[0.0476]$} & {$[0.0510]$} & {$[0.255]$} & {$[0.254]$} \\
\hline \multirow[t]{2}{*}{ Home_match $>1,300 \&<1,400 m$} & $0.515^{*}$ & $0.513^{*}$ & $0.498^{*}$ & 1.085 & 1.081 \\
\hline & {$[0.197]$} & {$[0.196]$} & {$[0.193]$} & {$[0.205]$} & {$[0.205]$} \\
\hline \multirow[t]{2}{*}{ Away_match $<300 m$} & $0.128 * * *$ & $0.128 * * *$ & $0.127 * * *$ & $0.200 * * *$ & $0.200 * * *$ \\
\hline & {$[0.0147]$} & {$[0.0150]$} & {$[0.0155]$} & {$[0.0634]$} & {$[0.0634]$} \\
\hline \multirow[t]{2}{*}{ Away_match $>300 \&<400 m$} & $0.816^{*}$ & $0.816^{*}$ & $0.803 *$ & $0.466 * * *$ & $0.466 * * *$ \\
\hline & {$[0.0916]$} & [0.0929] & {$[0.0975]$} & {$[0.0503]$} & {$[0.0503]$} \\
\hline \multirow[t]{2}{*}{ Away_match $>400 \&<500 m$} & $0.477 * * *$ & $0.477 * * *$ & $0.467 * * *$ & $0.556 * * *$ & $0.555^{* * *}$ \\
\hline & {$[0.0706]$} & {$[0.0713]$} & {$[0.0712]$} & {$[0.0719]$} & {$[0.0719]$} \\
\hline \multirow[t]{2}{*}{ Away_match $>500 \&<600 m$} & $0.239 * * *$ & $0.239 * * *$ & $0.237 * * *$ & $0.471 * * *$ & $0.470 * * *$ \\
\hline & {$[0.0781]$} & {$[0.0780]$} & {$[0.0762]$} & {$[0.117]$} & {$[0.117]$} \\
\hline \multirow[t]{2}{*}{ Away_match $>600 \&<700 m$} & $0.283 * * *$ & $0.283 * * *$ & $0.281 * * *$ & $0.534 * * *$ & $0.534 * * *$ \\
\hline & {$[0.0213]$} & {$[0.0214]$} & {$[0.0223]$} & {$[0.0918]$} & {$[0.0917]$} \\
\hline \multirow[t]{2}{*}{ Away_match $>700 \&<800 m$} & $0.109 * * *$ & $0.109 * * *$ & $0.108 * * *$ & $0.386 * * *$ & $0.386 * * *$ \\
\hline & {$[0.0178]$} & {$[0.0179]$} & {$[0.0178]$} & {$[0.0854]$} & {$[0.0853]$} \\
\hline Away_match $>800 \&<900 m$ & 0.724 & 0.723 & 0.716 & $0.731 * * *$ & $0.731 * * *$ \\
\hline & [0.664] & {$[0.664]$} & {$[0.658]$} & {$[0.0737]$} & {$[0.0736]$} \\
\hline Away_match $>900 \&<1,000 m$ & $0.371 * * *$ & $0.371 * * *$ & $0.370 * * *$ & $0.741 * *$ & $0.740 * *$ \\
\hline & {$[0.0513]$} & {$[0.0512]$} & {$[0.0518]$} & {$[0.0907]$} & [0.0906] \\
\hline Away_match $>1,000 \&<1,100 m$ & $0.327 * * *$ & $0.326 * * *$ & $0.324 * * *$ & $0.779 * *$ & $0.778 * *$ \\
\hline & {$[0.0552]$} & {$[0.0547]$} & {$[0.0536]$} & {$[0.0870]$} & [0.0869] \\
\hline Away_match $>1,100 \&<1,200 m$ & 0.439 & 0.439 & 0.437 & 0.926 & 0.926 \\
\hline & {$[0.281]$} & {$[0.281]$} & {$[0.281]$} & {$[0.112]$} & [0.112] \\
\hline Away_match $>1,200 \&<1,300 m$ & $0.285 * * *$ & $0.285^{* * *}$ & $0.282 * * *$ & $1.343^{* *}$ & $1.341 * *$ \\
\hline & {$[0.0491]$} & {$[0.0494]$} & {$[0.0498]$} & {$[0.186]$} & {$[0.186]$} \\
\hline Away_match $>1,300 \&<1,400 m$ & $0.386 * * *$ & $0.385^{* * *}$ & $0.385^{* * *}$ & 0.889 & 0.888 \\
\hline & {$[0.117]$} & {$[0.116]$} & {$[0.116]$} & {$[0.126]$} & {$[0.126]$} \\
\hline Observations & 270,555 & 270,555 & 270,555 & 270,555 & 270,555 \\
\hline Climate controls & YES & YES & YES & YES & YES \\
\hline Time controls & YES & YES & YES & YES & YES \\
\hline Seasonal controls & YES & YES & YES & YES & YES \\
\hline Derby dummy & YES & YES & YES & YES & YES \\
\hline Week fixed effects & NO & YES & YES & NO & YES \\
\hline Day fixed effects & NO & NO & YES & NO & NO \\
\hline
\end{tabular}

since with this approach all rings include the census tracts that lie closest to the stadium, i.e., those that are most likely to show a significant increase in their crime counts. 
Census tract fixed effects

NO

NO

NO

YES

YES

Notes: Negative binomial results of estimating Eq. (2). Dependent variable theft counts. Climate controls include: average rainfall, average number of sun hours, average temperature, average pressure and average wind speed. Time controls include: day of the week, holiday indicator, week of the year, weekend and month. Seasonal controls include dummies for summer (mainly September) and winter. Coefficients reported as incidence rate ratios. p-values in square brackets. $* * *$ $\mathrm{p}<0.01, * * \mathrm{p}<0.05, * \mathrm{p}<0.1$

Table 6. Non-cumulative rings. Negative binomial. Assaults.

\begin{tabular}{|c|c|c|c|c|c|}
\hline VARIABLES & (1) & $(2)$ & $(3)$ & $(4)$ & $(5)$ \\
\hline \multirow[t]{2}{*}{ Home_match $<300 m$} & $1.476 * * *$ & $1.462 * * *$ & $1.460 * * *$ & $2.750 * *$ & $2.770 * *$ \\
\hline & {$[0.110]$} & [0.112] & [0.129] & {$[1.348]$} & {$[1.356]$} \\
\hline \multirow[t]{2}{*}{ Home_match $>300 \&<400 m$} & $2.199 * * *$ & $2.187 * * *$ & $2.176 * * *$ & 0.972 & 0.974 \\
\hline & [0.162] & {$[0.162]$} & {$[0.195]$} & [0.209] & [0.209] \\
\hline \multirow{2}{*}{ Home_match $>400 \&<500 m$} & $1.990 * *$ & $1.989 * *$ & $1.964 *$ & 1.127 & 1.131 \\
\hline & {$[0.692]$} & {$[0.693]$} & [0.689] & {$[0.300]$} & [0.301] \\
\hline \multirow[t]{2}{*}{ Home_match $>500 \&<600 m$} & 1.680 & 1.674 & 1.649 & 0.731 & 0.733 \\
\hline & {$[1.051]$} & [1.047] & [1.036] & [0.342] & [0.342] \\
\hline \multirow[t]{2}{*}{ Home_match $>600 \&<700 m$} & $1.548 * * *$ & $1.544 * * *$ & $1.554 * * *$ & 0.884 & 0.887 \\
\hline & {$[0.190]$} & [0.188] & {$[0.205]$} & [0.311] & [0.313] \\
\hline \multirow[t]{2}{*}{ Home_match $>700 \&<800 m$} & 0.870 & 0.867 & 0.862 & 0.669 & 0.671 \\
\hline & [0.476] & {$[0.473]$} & [0.465] & {$[0.228]$} & [0.229] \\
\hline \multirow{2}{*}{ Home_match $>800 \&<900 m$} & 1.409 & 1.403 & 1.393 & 1.152 & 1.156 \\
\hline & {$[0.330]$} & [0.329] & {$[0.330]$} & [0.292] & [0.293] \\
\hline \multirow[t]{2}{*}{ Home_match $>900 \&<1,000 m$} & 0.895 & 0.893 & 0.893 & 0.748 & 0.751 \\
\hline & [0.139] & {$[0.138]$} & {$[0.150]$} & [0.214] & {$[0.215]$} \\
\hline \multirow[t]{2}{*}{ Home_match $>1,000 \&<1,100 m$} & 1.699 & 1.694 & 1.679 & $1.645^{*}$ & $1.649^{*}$ \\
\hline & {$[0.771]$} & [0.769] & {$[0.749]$} & [0.441] & [0.443] \\
\hline \multirow[t]{2}{*}{ Home_match $>1,100 \&<1,200 m$} & $0.726 * * *$ & $0.723 * * *$ & $0.721 * * *$ & 0.788 & 0.791 \\
\hline & {$[0.0478]$} & {$[0.0490]$} & {$[0.0493]$} & [0.164] & [0.164] \\
\hline \multirow[t]{2}{*}{ Home_match $>1,200 \&<1,300 m$} & 0.985 & 0.982 & 0.980 & 1.028 & 1.032 \\
\hline & [0.196] & [0.197] & [0.201] & [0.302] & [0.303] \\
\hline \multirow[t]{2}{*}{ Home_match $>1,300 \&<1,400 m$} & 0.762 & 0.760 & 0.756 & 1.352 & 1.360 \\
\hline & {$[0.497]$} & [0.496] & {$[0.488]$} & {$[0.405]$} & [0.407] \\
\hline \multirow[t]{2}{*}{ Away_match $<300 m$} & $0.262 * * *$ & $0.261 * * *$ & $0.261 * * *$ & 1.090 & 1.093 \\
\hline & {$[0.0215]$} & {$[0.0213]$} & {$[0.0220]$} & {$[0.488]$} & {$[0.490]$} \\
\hline \multirow[t]{2}{*}{ Away_match $>300 \&<400 m$} & 1.048 & 1.047 & 1.047 & $0.728 * *$ & $0.727 * *$ \\
\hline & {$[0.0853]$} & {$[0.0857]$} & [0.0883] & [0.117] & {$[0.117]$} \\
\hline \multirow[t]{2}{*}{ Away_match $>400 \&<500 m$} & $0.645^{* *}$ & $0.645^{* *}$ & $0.643^{* *}$ & $0.698^{*}$ & $0.699 *$ \\
\hline & {$[0.141]$} & {$[0.141]$} & {$[0.142]$} & [0.142] & [0.142] \\
\hline \multirow[t]{2}{*}{ Away_match $>500 \&<600 m$} & 0.448 & 0.448 & 0.448 & 0.773 & 0.773 \\
\hline & [0.229] & {$[0.228]$} & [0.227] & [0.244] & {$[0.244]$} \\
\hline \multirow[t]{2}{*}{ Away_match $>600 \&<700 m$} & 0.912 & 0.911 & 0.911 & 0.883 & 0.885 \\
\hline & {$[0.0943]$} & {$[0.0952]$} & {$[0.0945]$} & [0.215] & [0.215] \\
\hline \multirow[t]{2}{*}{ Away_match $>700 \&<800 m$} & $0.403 * * *$ & $0.403 * * *$ & $0.402 * * *$ & $0.657 *$ & $0.657 *$ \\
\hline & {$[0.0593]$} & {$[0.0593]$} & {$[0.0599]$} & [0.151] & {$[0.151]$} \\
\hline \multirow[t]{2}{*}{ Away_match $>800 \&<900 m$} & 0.649 & 0.648 & 0.648 & $0.712 *$ & $0.713 *$ \\
\hline & [0.307] & [0.307] & [0.307] & {$[0.144]$} & {$[0.144]$} \\
\hline Away_match $>900 \&<1,000 m$ & 0.785 & 0.786 & 0.785 & $0.513 * * *$ & $0.513 * * *$ \\
\hline & [0.185] & [0.186] & [0.186] & [0.109] & [0.109] \\
\hline Away_match $>1,000 \&<1,100 m$ & 0.876 & 0.875 & 0.874 & $1.654 * *$ & $1.654 * *$ \\
\hline & [0.167] & [0.166] & [0.165] & {$[0.339]$} & [0.339] \\
\hline Away_match $>1,100 \&<1,200 m$ & 0.975 & 0.973 & 0.969 & $0.663 * * *$ & $0.664 * * *$ \\
\hline & {$[0.0617]$} & {$[0.0601]$} & {$[0.0585]$} & {$[0.0962]$} & [0.0963] \\
\hline Away_match $>1,200 \&<1,300 m$ & 1.007 & 1.007 & 1.004 & 1.211 & 1.212 \\
\hline & {$[0.478]$} & {$[0.478]$} & {$[0.475]$} & {$[0.243]$} & {$[0.243]$} \\
\hline Away_match $>1,300 \&<1,400 m$ & $0.546 * * *$ & $0.546 * * *$ & $0.545 * * *$ & 0.957 & 0.959 \\
\hline & {$[0.104]$} & [0.104] & {$[0.103]$} & {$[0.220]$} & {$[0.221]$} \\
\hline Observations & 270,555 & 270,555 & 270,555 & 270,555 & 270,555 \\
\hline Climate controls & YES & YES & YES & YES & YES \\
\hline Time controls & YES & YES & YES & YES & YES \\
\hline Seasonal controls & YES & YES & YES & YES & YES \\
\hline Derby dummy & YES & YES & YES & YES & YES \\
\hline
\end{tabular}




\begin{tabular}{|c|c|c|c|c|c|}
\hline Week fixed effects & NO & YES & YES & $\mathrm{NO}$ & YES \\
\hline Day fixed effects & NO & NO & YES & $\mathrm{NO}$ & NO \\
\hline Census tract fixed effects & NO & NO & NO & YES & YES \\
\hline
\end{tabular}

Notes: Negative binomial results of estimating Eq. (2). Dependent variable assaults counts. Climate controls include: average rainfall, average number of sun hours, average temperature, average pressure and average wind speed. Time controls include: day of the week, holiday indicator, week of the year, weekend and month. Seasonal controls include dummies for summer (mainly September) and winter. Coefficients reported as incidence rate ratios. p-values in square brackets. $* * *$ $\mathrm{p}<0.01, * * \mathrm{p}<0.05, * \mathrm{p}<0.1$.

The marked increase in assaults in the census tracts closest to the stadium are presumably attributable, as previously explained, to the fact that a greater number of social interactions, and possible rivalries between opposing football fans, can lead to clashes and fighting. In the case of football matches there appears to be other impacts on assaults at more distances computed from the stadium. Another increase in the number of assaults during home football matches occurs in census tracts located within 1,000 and 1,100 meters of the stadium. The effects found in columns not using census tracts fixed effects point out to the relevance to account for such effects that take into account the presence of specific places (bars, pubs, parking areas, etc.) that could explain the spatial patterns observed.

Finally, the results for the away matches show that there is a lower probability of suffering a crime around the stadium those days that FCB plays away, maybe due to a displacement effect of individuals towards the city center and other recreational areas of the city to watch the match. Note that also these results have policy implications for the deployment of policy even on away-match dates.

Similar results, in terms of the role of (temporal) agglomeration in inducing crime, are presented in Gil and Macis (2015) who studied the impact of a temporary, large and unexpected shift inward of "demand" (referring to the effective reduction in population in Washington DC due to the government shutdown in October 2013) on criminal activity. The authors found a drop in crime, confirming that, as it is our case, demand-side factors such as population are important determinants of criminal activity.

Our results provide a clearer indication of the distance at which the impact of football on crime disappears. In the case of thefts, distance decay is clear, although not homogeneous as there are specific rings that present higher levels of thefts than rings that are closer to the stadium. Again, this presumably reflects the fact that certain circumstances of an area are likely to increase the number of thefts. The effect of football matches on the number of thefts seems to disappear in census tracts located at an average distance of 900 meters from the stadium while, as just mentioned, for the case of assaults it seems to disappear at an average distance of 300 meters. 
Figure 3. Negative binomial estimates for non-cumulative rings (100 meters)
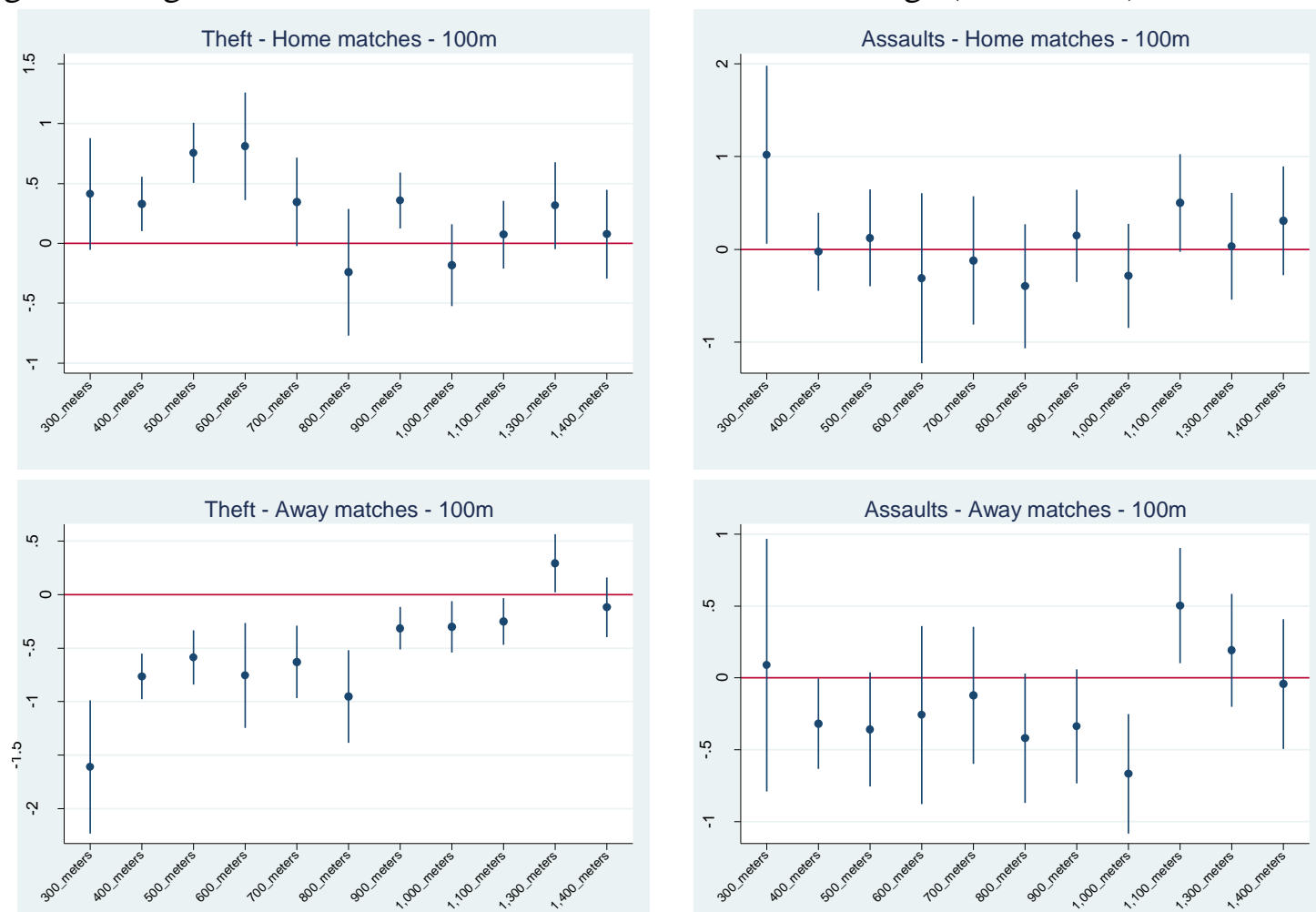

Notes: Graphical representation of the negative binomial results of estimating Eq. (2). Dependent variable crime counts. Climate controls include: average rainfall, average number of sun hours, average temperature, average pressure and average wind speed. Time controls include: day of the week, holiday indicator, week of the year, weekend and month. Seasonal controls include dummies for summer (mainly September) and winter. Coefficients reported as incidence rate ratios.

Overall, our results for the whole city and those obtained when focusing around the stadium could also be reflecting changes in match day law enforcement. Precisely to prevent the occurrence of incidents, to guarantee the security of citizens and also to prevent other types of criminal activity, large numbers of police officers are usually mobilized on match days. The only information we could obtain in this regard is the estimation made by Mossos d'Esquadra that an average of 246 police officers are required to police "high risk" games, such as those between FCB and historic rival Real Madrid CF. Unfortunately, we do not have precise information regarding the exact location of police forces or the deployment of local police officers (Guardia Urbana) during match days. However, the fact that we know that more police officers are deployed during these days can be useful in interpreting our results which should be viewed as observed changes in equilibrium crime, reflecting enforcement and criminal activity. More precisely, if police officers have a deterrent effect on illegal activities our results are reinforced because we obtain a positive impact of football matches on crime, especially close to the FCB Stadium, even though we know that police presence is increased on football days in the area surrounding the stadium. 


\section{Conclusions}

This paper has analyzed the overall effects and the spatial displacement/concentration effects of football matches on thefts (mainly pick pocketing) and assaults (related to hooliganism in the present set up) in an urban context. Using an OLS regression approach we first estimated the impact on crime across the city of Barcelona of Football Club Barcelona playing at home and away. The results show clear evidence of an increase in thefts when FCB play at home; however, this trend seems not to be present for assaults or when FCB play away.

In order to analyze in depth how large crowds attending football matches can impact criminal behavior, we analyzed crime patterns around the FCB stadium and found that both the number of thefts and assaults increased significantly. This pattern was confirmed using an ESDA and by undertaking a regression analysis. Specifically, we found that the number of thefts increased significantly in census tracts located within a 900-meter radius of the stadium, while the increase recorded in assaults is more prominent in areas in census tracts located within a 300-meter radius of the stadium.

These results - the overall effects and the spatial crime patterns - point to two different crime generating processes. First, the spatial patterns indicate a clear concentration effect for both types of crime. In the case of thefts, large crowds attract pickpockets that perceive (in terms of the Routine Activity Theory) that their rewards will be higher and their probability of being apprehended lower, despite the increase in police presence around the stadium. The attractiveness of the targets may also drive part of this effect; the presence of spectators carrying cameras and cash, in addition to a large number of inattentive tourists, serve as magnets for pickpockets.

In the case of assaults, the spatial patterns also point to a concentration effect around the stadium when FCB play at home pointing out to the presence of interpersonal violence or hooliganism. Indeed, in the census tracts closest to the stadium (and in the census tract in which the stadium is located) the number of assaults increases significantly. However, the absence of any effects for the city as a whole for regular matches (whether FCB are at playing home or away) suggests a second effect, that of displacement from other areas of the city to the stadium on match days. A possible explanation for this might be the similar profiles shared by football fans and potential offenders. The results reported in this study, however, do not control for the extra policing provided on match days, as no data are available. Yet, we have been able to show the significant increase in the number of thefts across the city of Barcelona even though there is a greater presence of police officers when FCB play at home. 
Thus, in addition to shedding light on the effects of football matches on crime in an urban context, this paper may also be used for the effective allocation of police patrols in the city of Barcelona. As the ESDA and kernel density function analyses show, not only does the number of thefts in the vicinity of the stadium increase, there is also a rise in such crimes in the center of the city and in and around large transport hubs, including metro and railway stations. This indicates that additional police officers should be assigned to the area around the stadium and to certain parts of the city, including the city center, which suffers (approximately) half of the overall increase in the number of thefts.

The policy implications of our results are multiple. For instance, we have presented strong evidence of the increase in certain types of crime throughout the city of Barcelona when football matches are played, above all around the FCB Stadium. An increase in illegal activities is recorded in relation to the celebration of a private leisure activity such as football and, hence, additional public resources must be devoted to control for these negative externalities. While it is true that private institutions already contribute to public budgets, the extra costs society has to face as a result of their activities need to be taken into consideration. Operationally, the police should not only monitor crowds at the entrance to the stadium, as they do now. As we have shown, the impact of football matches extends over a radius (close to) $1 \mathrm{~km}$ in the case of thefts and around 300 meters in the case of assaults. 


\section{References}

Ahlfeldt, G. M., Kavetsos, G. (2013). Should I wish on a stadium? Measuring the average effect on the treated. The Econometrics of Sport, 189.

Allmers, S., Maennig, W. (2009). Economic impacts of the FIFA Soccer World Cups in France 1998, Germany 2006, and outlook for South Africa 2010, Eastern Economic Journal 35(4), 500-519.

Anderson, C.A. (2001). Heat and violence, Current Directions in Psychological Science, 3338 .

Anselin, L. (1995). Local indicators of spatial association - LISA, Geographical Analysis 27, 93-115.

Bailey, T.C., Gatrell, A.C., (1995). Interactive spatial data analysis. Harlow: Longman.

Benabou, R. (1993). Workings of a City: Location, Education and Production, Quarterly Journal of Economics, 108(3), 619-652.

Bowers, K.J., Johnson, S.D., Guerette, R.T., Summers, L., Poynton, S. (2011). Spatial displacement and diffusion of benefits among geographically focused policing initiatives: a meta-analytical review. Journal of Experimental Criminology, 7(4), 347-374.

Brantingham, P.L., Brantingham, P.J. (1993). Environment, Routine, and Situation: Toward a Pattern Theory of Crime, in: Routine Activity and Rational Choice, R.V.G. Clarke, R.V.G., Felson, M. (Eds.), New Brunswick, NJ: Transaction. 259-294.

Brantingham, P.L., Brantingham, P.J. (1995). Criminality of pace: crime generators and crime attractors, European Journal on Criminal. Policy and Research, 3, 1-26.

Campaniello, N. (2011). Mega events in sports and crime: evidence from the 1990 Football World Cup, Journal of Sports Economics, 1-23.

Card, D., Dahl, G.B. (2011). Family violence and football: the effect of unexpected emotional cues on violent behavior, Quarterly Journal of Economics 126(1), 103-143.

Cherry, T., List, J. (2002). Aggregation bias in the economic model of crime, Economic Letters, 81-86.

Chainey, S.P., Tompson, L., Uhlig, S. (2008). The utility of hotspot mapping for predicting spatial patterns of crime, Security Journal, 21, 4-28.

Cohen, L.E., Felson, M. (1979). Social change and crime rate trends: A routine activity approach, American Sociological Review, 588-608.

Currie, J., Yelowitz, A. (2000). Are Public Housing Projects Good for Kids, Journal of Public Economics, 75, 99-124.

Dahl, G., DellaVigna, S. (2009). Does movie violence increase violent crime?, Quarterly Journal of Economics, 124, 677-734. 
DiDomizio, M., Caruso, R. (2014). Hooliganism and demand for football in Italy: Attendance and counter-violence policy evaluation, German Economic Review 16(2), 123-137.

Dohmen, T., Falk, A., Huffman, D., Sunde, U. (2006). Seemingly irrelevant events affect perceptions and expectations-The FIFA World Cup 2006 as a natural experiment, IZA Discussion Paper No. 2275.

Duncan, B., Mansour, H., Rees, D.I. (2016). It's Just a Game: The Super Bowl and Low Birth Weight, Journal of Human Resources, 0615-7213R.

Ellison, G., Glaeser, E.L., Kerr, W.R. (2010). What Causes Industry Agglomeration? Evidence from Coagglomeration Patterns, American Economic Review, 100(3), 1195-1213.

Eren, O., Mocan, N. (2017). Emotional judges and unlucky juveniles. American Economic Journal: Applied Economics. Forthcoming.

Gil, R., Macis, M. (2015). 'Ain't No Rest for the Wicked': Population, Crime, and the 2013 Government Shutdown. IZA DP No.8864.

Glaeser, E.L., Sacerdote, B., Scheinkman, J.A. (1996). Crime and social interactions, Quarterly Journal of Economics, 111(2): 507-548.

Hagn, F., Maennig, W. (2008). Employment effects of the Football World Cup 1974 in Germany, Labour Economics, 15(5), 1062-1075.

Jacob, B., Lefgren, L., Moretti, E. (2004). The dynamics of criminal behavior: evidence from weather shocks, Journal of Human Resources, 42(3), 489-527.

Kirby, S., Francis, B., O'Flaherty, R. (2013). Can the FIFA World Cup Football (soccer) tournament be associated with an increase in domestic abuse?, Journal of Research in Crime and Delinquency, 1-18.

Kurland, J., Johnson, S.D., Tilley, N. (2014). Offenses around stadiums: A natural experiment on crime attraction and generation, Journal of research in crime and delinquency, $51(1), 5-28$

Madensen, T.D., Eck, J.E. (2008). Spectator violence in stadiums, problem-oriented guides for police. Problem-Specific Guides Series No 54. Community Oriented Policing Services (COPS). US Department of Justice.

Marie, O. (2011). Football matches: the effects on crime, Centre for Economic Performance LSE Discussion Paper No 348.

Marie, O. (2016). Police and thieves in the stadium: measuring the (multiple) effects of football matches on crime, Journal of the Royal Statistical Society: Series A (Statistics in Society), 179 (1), 273-292.

Matheson, V.A., Baade, R.A. (2004). Mega-sporting events in developing nations: playing the way to prosperity?, South African Journal of Economics 72(5), 1085-1096. 
Montolio, D., Planells-Struse, S. (2016). How time shapes crime: the displacement effects of football matches in the city of Barcelona. Regional Science and Urban Economics, 61, 99113.

Munyo, I., Rossi, M.A. (2013). Frustration, euphoria, and violent crime. Journal of Economic Behavior \& Organization, 89, 136-142.

Poutvaara, P., Priks, M. (2009). The effect of police intelligence on group violence: Evidence from reassignments in Sweden, Journal of Public Economics, 93(3), 403-411.

Priks, M. (2010). Does frustration lead to violence? Evidence from the Swedish hooligan scene, Kyklos 63(3), 450-460.

Rauch, J.E. (1993). Productivity Gains from Geographic Concentration of Human Capital, Journal of Urban Economics, 34(3), 380-400.

Rossi-Hansberg, E., Sarte, P.D., Owens, R.I. (2010). Housing Externalities, Journal of Political Economy, 118(3), 485-535.

Russell, G.W. (2004). Sport riots: A social-psychological review, Aggression and violent behavior, 9(4), 353-378.

Süssmuth, B., Heyne, M., Maennig, W. (2010). Induced civic pride and integration, Oxford Bulletin of Economics and Statistics, 72(2), 202-220.

Vohs, K., Baumeister, R., Loewenstein, G. (2007). Do Emotions Help or Hurt Decision Making? A Hedgefoxian Perspective. Russell, New York.

Williamson, D., McLafferty, S., Goldsmith, V., Mollenkopf, J., McGuire, P. (1998). Smoothing crime incident data: new methods for determining the bandwidth in Kernel estimation, $18^{\text {th }}$ ESRI International User Conference, San Diego 27-31 July 1998. 


\section{Appendix A.}

Table A.1. OLS estimations. Effect of home and away matches on theft and assault counts. Day after the match.

\begin{tabular}{|c|c|c|c|}
\hline VARIABLES & $(1)$ & $(2)$ & (4) \\
\hline & Thefts & Thefts & Thefts \\
\hline \multirow[t]{2}{*}{ Home match } & 12.17 & 10.02 & $12.13^{*}$ \\
\hline & (7.824) & $(7.653)$ & $(7.330)$ \\
\hline \multirow[t]{2}{*}{ Away match } & 1.626 & -2.831 & -1.374 \\
\hline & $(6.232)$ & $(6.095)$ & $(5.796)$ \\
\hline \multirow[t]{2}{*}{ Day after } & -0.496 & -0.597 & 0.264 \\
\hline & $(3.363)$ & $(3.282)$ & $(3.217)$ \\
\hline \multirow[t]{2}{*}{ Constant } & $467.6 * * *$ & $443.1 * * *$ & $418.8 * * *$ \\
\hline & $(22.24)$ & $(21.56)$ & $(18.52)$ \\
\hline R-squared & 0.544 & 0.583 & 0.635 \\
\hline Durbin-Watson (original) & 1.25 & 1.24 & 1.51 \\
\hline \multirow[t]{2}{*}{ Durbin-Watson (transformed) } & 2.02 & 2.04 & 1.96 \\
\hline & Assaults & Assaults & Assaults \\
\hline \multirow[t]{2}{*}{ Home match } & -3.702 & -3.515 & -3.827 \\
\hline & $(3.242)$ & (2.994) & $(2.911)$ \\
\hline \multirow[t]{2}{*}{ Away match } & -2.406 & -2.335 & -2.647 \\
\hline & $(3.150)$ & (2.894) & $(2.816)$ \\
\hline \multirow[t]{2}{*}{ Day after } & -0.546 & -0.574 & -0.581 \\
\hline & $(0.566)$ & $(0.562)$ & $(0.559)$ \\
\hline \multirow[t]{2}{*}{ Constant } & $26.72 * * *$ & $25.20 * * *$ & $25.73 * * *$ \\
\hline & $(1.953)$ & $(2.114)$ & $(2.207)$ \\
\hline R-squared & 0.196 & 0.221 & 0.227 \\
\hline Durbin-Watson (original) & 1.96 & 1.99 & 2.00 \\
\hline Durbin-Watson (transformed) & 1.98 & 1.98 & 1.98 \\
\hline Observations & 1,214 & 1,214 & 1,214 \\
\hline Climate controls & $\mathrm{NO}$ & YES & YES \\
\hline Time controls & YES & YES & YES \\
\hline Year fixed effects & NO & NO & YES \\
\hline Seasonal controls & YES & YES & YES \\
\hline Derby dummy & YES & YES & YES \\
\hline
\end{tabular}

Notes: OLS results of estimating Eq. (1) using the corrected for first-order serially-correlated residuals using the Prais-Winsten transformed regression estimator. Dependent variable crime counts. Climate controls include: average rainfall, average number of sun hours, average temperature, average pressure and average wind speed. Time controls include: day of the week, holiday indicator, week of the year, weekend and month. Seasonal controls include dummies for summer (mainly September) and winter. Robust standard errors are shown in parentheses. *** $\mathrm{p}<0.01, * * \mathrm{p}<0.05,{ }^{*} \mathrm{p}<0.1$. 
Appendix B.

Table B.1. Non-cumulative rings (100 meters). OLS results for thefts and assaults.

\begin{tabular}{|c|c|c|c|c|}
\hline VARIABLES & Thefts & Thefts & Assaults & Assaults \\
\hline \multirow[t]{2}{*}{ Home_match $<300 m$} & 0.147 & 0.146 & $0.0909 * *$ & $0.0911 * *$ \\
\hline & $(0.0953)$ & $(0.0953)$ & $(0.0405)$ & $(0.0405)$ \\
\hline \multirow[t]{2}{*}{ Home_match $>300 \&<400 m$} & $0.391 * * *$ & $0.390 * * *$ & -0.0224 & -0.0222 \\
\hline & $(0.0674)$ & $(0.0674)$ & $(0.0286)$ & $(0.0286)$ \\
\hline \multirow[t]{2}{*}{ Home_match $>400 \&<500 m$} & $0.362 * * *$ & $0.361 * * *$ & 0.0228 & 0.0230 \\
\hline & $(0.0550)$ & $(0.0551)$ & $(0.0234)$ & $(0.0234)$ \\
\hline \multirow[t]{2}{*}{ Home_match $>500 \&<600 m$} & $0.136^{* *}$ & $0.135^{* *}$ & -0.0148 & -0.0146 \\
\hline & $(0.0674)$ & $(0.0674)$ & $(0.0286)$ & $(0.0286)$ \\
\hline \multirow[t]{2}{*}{ Home_match $>600 \&<700 m$} & 0.0536 & 0.0524 & -0.00834 & -0.00812 \\
\hline & $(0.0550)$ & $(0.0551)$ & $(0.0234)$ & $(0.0234)$ \\
\hline \multirow{2}{*}{ Home_match $>700 \&<800 m$} & -0.0359 & -0.0370 & -0.0220 & -0.0218 \\
\hline & $(0.0510)$ & $(0.0510)$ & $(0.0216)$ & $(0.0216)$ \\
\hline \multirow[t]{2}{*}{ Home_match $>800 \&<900 m$} & $0.135 * * *$ & $0.134 * * *$ & 0.00798 & 0.00820 \\
\hline & $(0.0450)$ & $(0.0450)$ & $(0.0191)$ & $(0.0191)$ \\
\hline \multirow[t]{2}{*}{ Home_match $>900 \&<1,000 m$} & -0.0404 & -0.0415 & -0.0231 & -0.0228 \\
\hline & $(0.0510)$ & $(0.0510)$ & $(0.0216)$ & $(0.0216)$ \\
\hline \multirow[t]{2}{*}{ Home_match $>1,000 \&<1,100 m$} & 0.0104 & 0.00929 & 0.0254 & 0.0256 \\
\hline & $(0.0427)$ & $(0.0427)$ & $(0.0181)$ & $(0.0181)$ \\
\hline \multirow{2}{*}{ Home_match $>1,100 \&<1,200 m$} & 0.00868 & 0.00755 & -0.0199 & -0.0197 \\
\hline & $(0.0427)$ & $(0.0427)$ & $(0.0181)$ & $(0.0181)$ \\
\hline \multirow{2}{*}{ Home_match $>1,200 \&<1,300 m$} & 0.0290 & 0.0278 & 0.00117 & 0.00139 \\
\hline & $(0.0477)$ & $(0.0477)$ & $(0.0202)$ & $(0.0203)$ \\
\hline \multirow[t]{2}{*}{ Home_match $>1,300 \&<1,400 m$} & -0.00314 & -0.00427 & 0.0209 & 0.0212 \\
\hline & $(0.0510)$ & $(0.0510)$ & $(0.0216)$ & $(0.0216)$ \\
\hline \multirow[t]{2}{*}{ Away_match $<300 m$} & $-0.211 * * *$ & $-0.212 * * *$ & 0.00562 & 0.00569 \\
\hline & $(0.0664)$ & $(0.0664)$ & $(0.0282)$ & $(0.0282)$ \\
\hline \multirow[t]{2}{*}{ Away_match $>300 \&<400 m$} & $-0.397 * * *$ & $-0.397 * * *$ & $-0.0737 * * *$ & $-0.0736 * * *$ \\
\hline & $(0.0470)$ & $(0.0470)$ & $(0.0200)$ & $(0.0200)$ \\
\hline \multirow[t]{2}{*}{ Away_match $>400 \&<500 m$} & $-0.119 * * *$ & $-0.119 * * *$ & -0.0265 & -0.0264 \\
\hline & $(0.0384)$ & $(0.0384)$ & $(0.0163)$ & $(0.0163)$ \\
\hline \multirow[t]{2}{*}{ Away_match $>500 \&<600 m$} & -0.0663 & -0.0666 & -0.0105 & -0.0104 \\
\hline & $(0.0470)$ & $(0.0470)$ & $(0.0200)$ & $(0.0200)$ \\
\hline \multirow[t]{2}{*}{ Away_match $>600 \&<700 m$} & $-0.0777 * *$ & $-0.0781 * *$ & -0.00818 & -0.00811 \\
\hline & $(0.0384)$ & $(0.0384)$ & $(0.0163)$ & $(0.0163)$ \\
\hline \multirow[t]{2}{*}{ Away_match $>700 \&<800 m$} & $-0.0642 *$ & $-0.0645^{*}$ & -0.0219 & -0.0219 \\
\hline & $(0.0356)$ & $(0.0356)$ & $(0.0151)$ & $(0.0151)$ \\
\hline \multirow[t]{2}{*}{ Away_match $>800 \&<900 m$} & $-0.0685^{* *}$ & $-0.0689 * *$ & -0.0188 & -0.0187 \\
\hline & $(0.0314)$ & $(0.0314)$ & $(0.0133)$ & $(0.0133)$ \\
\hline Away_match $>900 \&<1,000 m$ & $-0.0592 *$ & $-0.0595^{*}$ & $-0.0428 * * *$ & $-0.0427 * * *$ \\
\hline & $(0.0356)$ & $(0.0356)$ & $(0.0151)$ & $(0.0151)$ \\
\hline Away_match $>1,000 \&<1,100 m$ & -0.0407 & -0.0410 & $0.0262 * *$ & $0.0263 * *$ \\
\hline & $(0.0298)$ & $(0.0298)$ & $(0.0127)$ & $(0.0127)$ \\
\hline Away_match $>1,100 \&<1,200 m$ & -0.0134 & -0.0137 & $-0.0368 * * *$ & $-0.0368 * * *$ \\
\hline & $(0.0298)$ & $(0.0298)$ & $(0.0127)$ & $(0.0127)$ \\
\hline Away_match $>1,200 \&<1,300 m$ & 0.0328 & 0.0325 & 0.0112 & 0.0112 \\
\hline & $(0.0333)$ & $(0.0333)$ & $(0.0141)$ & $(0.0141)$ \\
\hline Away_match $>1,300 \&<1,400 m$ & -0.0232 & -0.0235 & -0.00299 & -0.00293 \\
\hline & $(0.0356)$ & $(0.0356)$ & $(0.0151)$ & $(0.0151)$ \\
\hline Observations & 270,555 & 270,555 & 270,555 & 270,555 \\
\hline Climate controls & YES & YES & YES & YES \\
\hline Time controls & YES & YES & YES & YES \\
\hline Seasonal controls & YES & YES & YES & YES \\
\hline Derby dummy & YES & YES & YES & YES \\
\hline Week fixed effects & NO & YES & NO & YES \\
\hline Census tract fixed effects & YES & YES & YES & YES \\
\hline
\end{tabular}

Notes: OLS results of estimating Eq. (2). Dependent variable crime counts. Climate controls include: average rainfall, average number of sun hours, average temperature, average pressure and average wind speed. Time controls include: day of the week, holiday indicator, week of the year, weekend and month. Seasonal controls include dummies for summer (mainly September) and winter. Robust standard errors are shown in parentheses. $* * * \mathrm{p}<0.01, * * \mathrm{p}<0.05, * \mathrm{p}<0.1$. 
Table B.2. Non-cumulative rings (100 meters). Probit results for thefts and assaults.

\begin{tabular}{|c|c|c|c|c|c|c|}
\hline VARIABLES & Thefts & Thefts & Thefts & Assaults & Assaults & Assaults \\
\hline Home_match $<300 m$ & $\begin{array}{c}0.619 * * * \\
(0.155)\end{array}$ & $\begin{array}{c}0.605 * * * \\
(0.150)\end{array}$ & $\begin{array}{c}0.603 * * * \\
(0.151)\end{array}$ & $\begin{array}{c}0.202 \\
(0.203)\end{array}$ & $\begin{array}{c}0.184 * * * \\
(0.0669)\end{array}$ & $\begin{array}{c}0.184 * * * \\
(0.0684)\end{array}$ \\
\hline Home_match $>300 \&<400 m$ & $\begin{array}{c}0.659 * * * \\
(0.109)\end{array}$ & $\begin{array}{c}0.645^{* * * *} \\
(0.151)\end{array}$ & $\begin{array}{c}0.643 * * * \\
(0.151)\end{array}$ & $\begin{array}{c}0.612 * * * \\
(0.121)\end{array}$ & $\begin{array}{c}0.596 * * * \\
(0.0668)\end{array}$ & $\begin{array}{c}0.598 * * * \\
(0.0680)\end{array}$ \\
\hline Home_match $>400 \&<500 m$ & $\begin{array}{c}0.409 * * * \\
(0.0939)\end{array}$ & $\begin{array}{c}0.394 \\
(0.353)\end{array}$ & $\begin{array}{c}0.392 \\
(0.354)\end{array}$ & $\begin{array}{c}0.0856 \\
(0.125)\end{array}$ & $\begin{array}{c}0.0686 \\
(0.281)\end{array}$ & $\begin{array}{c}0.0699 \\
(0.284)\end{array}$ \\
\hline Home_match $>500 \&<600 m$ & $\begin{array}{c}0.340 * * * \\
(0.117)\end{array}$ & $\begin{array}{c}0.324 \\
(0.252)\end{array}$ & $\begin{array}{c}0.322 \\
(0.252)\end{array}$ & $\begin{array}{c}-0.232 \\
(0.187)\end{array}$ & $\begin{array}{c}-0.246 \\
(0.250)\end{array}$ & $\begin{array}{l}-0.246 \\
(0.252)\end{array}$ \\
\hline Home_match $>600 \&<700 m$ & $\begin{array}{c}0.103 \\
(0.104)\end{array}$ & $\begin{array}{l}0.0889 \\
(0.179)\end{array}$ & $\begin{array}{c}0.0874 \\
(0.180)\end{array}$ & $\begin{array}{l}-0.136 \\
(0.143)\end{array}$ & $\begin{array}{c}-0.153 * * \\
(0.0691)\end{array}$ & $\begin{array}{c}-0.152 * * \\
(0.0707)\end{array}$ \\
\hline Home_match $>700 \&<800 m$ & $\begin{array}{c}-0.431 * * * \\
(0.126)\end{array}$ & $\begin{array}{c}-0.449 * * * \\
(0.153)\end{array}$ & $\begin{array}{c}-0.451^{* * * *} \\
(0.154)\end{array}$ & $\begin{array}{l}-0.210 \\
(0.139)\end{array}$ & $\begin{array}{c}-0.223 * * \\
(0.101)\end{array}$ & $\begin{array}{c}-0.222^{* *} \\
(0.101)\end{array}$ \\
\hline Home_match $>800 \&<900 m$ & $\begin{array}{c}0.299 * * * \\
(0.0792)\end{array}$ & $\begin{array}{c}0.284 \\
(0.547)\end{array}$ & $\begin{array}{c}0.283 \\
(0.548)\end{array}$ & $\begin{array}{l}0.0310 \\
(0.105)\end{array}$ & $\begin{array}{l}0.0131 \\
(0.109)\end{array}$ & $\begin{array}{l}0.0154 \\
(0.111)\end{array}$ \\
\hline Home_match $>900 \&<1,000 m$ & $\begin{array}{c}0.0602 \\
(0.0978)\end{array}$ & $\begin{array}{l}0.0435 \\
(0.152)\end{array}$ & $\begin{array}{l}0.0414 \\
(0.153)\end{array}$ & $\begin{array}{c}-0.0266 \\
(0.123)\end{array}$ & $\begin{array}{r}-0.0429 \\
(0.172)\end{array}$ & $\begin{array}{c}-0.0408 \\
(0.174)\end{array}$ \\
\hline Home_match $>1,000 \&<1,100 m$ & $\begin{array}{c}0.0672 \\
(0.0816)\end{array}$ & $\begin{array}{l}0.0506 \\
(0.341)\end{array}$ & $\begin{array}{l}0.0488 \\
(0.341)\end{array}$ & $\begin{array}{r}-0.0235 \\
(0.103)\end{array}$ & $\begin{array}{c}-0.0380 \\
(0.128)\end{array}$ & $\begin{array}{c}-0.0371 \\
(0.126)\end{array}$ \\
\hline Home_match $>1,100 \&<1,200 m$ & $\begin{array}{c}0.115 \\
(0.0801)\end{array}$ & $\begin{array}{l}0.0987 \\
(0.311)\end{array}$ & $\begin{array}{l}0.0967 \\
(0.312)\end{array}$ & $\begin{array}{c}0.0793 \\
(0.0971)\end{array}$ & $\begin{array}{l}0.0613 \\
(0.223)\end{array}$ & $\begin{array}{l}0.0627 \\
(0.225)\end{array}$ \\
\hline Home_match $>1,200 \&<1,300 m$ & $\begin{array}{c}0.0424 \\
(0.0922)\end{array}$ & $\begin{array}{l}0.0271 \\
(0.175)\end{array}$ & $\begin{array}{l}0.0249 \\
(0.175)\end{array}$ & $\begin{array}{c}-0.0938 \\
(0.120)\end{array}$ & $\begin{array}{c}-0.108 \\
(0.0778)\end{array}$ & $\begin{array}{c}-0.106 \\
(0.0768)\end{array}$ \\
\hline Home_match $>1,300 \&<1,400 m$ & $\begin{array}{c}0.0776 \\
(0.0971) \\
\end{array}$ & $\begin{array}{l}0.0631 \\
(0.300) \\
\end{array}$ & $\begin{array}{c}0.0617 \\
(0.300) \\
\end{array}$ & $\begin{array}{l}-0.0266 \\
(0.123) \\
\end{array}$ & $\begin{array}{c}-0.0426 \\
(0.310) \\
\end{array}$ & $\begin{array}{r}-0.0407 \\
(0.307) \\
\end{array}$ \\
\hline Away_match $<300 m$ & $\begin{array}{c}-0.559 * * * \\
(0.135)\end{array}$ & $\begin{array}{c}-0.570 * * * \\
(0.154)\end{array}$ & $\begin{array}{c}-0.569 * * * \\
(0.154)\end{array}$ & $\begin{array}{c}-0.154 \\
(0.131)\end{array}$ & $\begin{array}{c}-0.160 * * \\
(0.0712)\end{array}$ & $\begin{array}{c}-0.160 * * \\
(0.0708)\end{array}$ \\
\hline Away_match $>300 \&<400 m$ & $\begin{array}{c}0.241 * * * \\
(0.0635)\end{array}$ & $\begin{array}{c}0.234 \\
(0.154)\end{array}$ & $\begin{array}{c}0.234 \\
(0.154)\end{array}$ & $\begin{array}{c}0.386 * * * \\
(0.0691)\end{array}$ & $\begin{array}{c}0.383 * * * \\
(0.0714)\end{array}$ & $\begin{array}{c}0.382 * * * \\
(0.0714)\end{array}$ \\
\hline Away_match $>400 \&<500 m$ & $\begin{array}{l}-0.0673 \\
(0.0586)\end{array}$ & $\begin{array}{c}-0.0734 \\
(0.241)\end{array}$ & $\begin{array}{r}-0.0732 \\
(0.241)\end{array}$ & $\begin{array}{l}-0.0411 \\
(0.0704)\end{array}$ & $\begin{array}{c}-0.0468 \\
(0.132)\end{array}$ & $\begin{array}{c}-0.0470 \\
(0.132)\end{array}$ \\
\hline Away_match $>500 \&<600 m$ & $\begin{array}{c}-0.502 * * * \\
(0.0916)\end{array}$ & $\begin{array}{c}-0.511 * * * \\
(0.158)\end{array}$ & $\begin{array}{c}-0.511 * * * \\
(0.158)\end{array}$ & $\begin{array}{c}-0.256^{* *} \\
(0.099)\end{array}$ & $\begin{array}{c}-0.26 \text { *** } \\
(0.093)\end{array}$ & $\begin{array}{c}-0.26 * * * \\
(0.093)\end{array}$ \\
\hline Away_match $>600 \&<700 m$ & $\begin{array}{c}-0.329 * * * \\
(0.0672)\end{array}$ & $\begin{array}{c}-0.335^{* *} \\
(0.154)\end{array}$ & $\begin{array}{c}-0.335^{* *} \\
(0.154)\end{array}$ & $\begin{array}{c}-0.154 * * \\
(0.0757)\end{array}$ & $\begin{array}{c}-0.158 * * \\
(0.0731)\end{array}$ & $\begin{array}{c}-0.158 * * \\
(0.0732)\end{array}$ \\
\hline Away_match $>700 \&<800 m$ & $\begin{array}{c}-0.685^{* * * *} \\
(0.0787)\end{array}$ & $\begin{array}{c}-0.694 * * * \\
(0.160)\end{array}$ & $\begin{array}{c}-0.694 * * * \\
(0.160)\end{array}$ & $\begin{array}{l}-0.25 * * * \\
(0.0750)\end{array}$ & $\begin{array}{c}-0.257 * * \\
(0.109)\end{array}$ & $\begin{array}{c}-0.257 * * \\
(0.109)\end{array}$ \\
\hline Away_match $>800 \&<900 m$ & $\begin{array}{c}0.0334 \\
(0.0458)\end{array}$ & $\begin{array}{l}0.0261 \\
(0.383)\end{array}$ & $\begin{array}{l}0.0260 \\
(0.383)\end{array}$ & $\begin{array}{l}-0.22 * * * \\
(0.0651)\end{array}$ & $\begin{array}{c}-0.234 \\
(0.160)\end{array}$ & $\begin{array}{l}-0.235 \\
(0.160)\end{array}$ \\
\hline Away_match $>900 \&<1,000 m$ & $\begin{array}{c}0.0273 \\
(0.0521)\end{array}$ & $\begin{array}{l}0.0196 \\
(0.192)\end{array}$ & $\begin{array}{l}0.0193 \\
(0.192)\end{array}$ & $\begin{array}{l}-0.22 * * * \\
(0.0737)\end{array}$ & $\begin{array}{c}-0.232 * * \\
(0.101)\end{array}$ & $\begin{array}{c}-0.232 * * \\
(0.101)\end{array}$ \\
\hline Away_match $>1,000 \&<1,100 m$ & $\begin{array}{l}-0.102 * * \\
(0.0462)\end{array}$ & $\begin{array}{l}-0.110 \\
(0.307)\end{array}$ & $\begin{array}{l}-0.110 \\
(0.307)\end{array}$ & $\begin{array}{l}-0.0579 \\
(0.0551)\end{array}$ & $\begin{array}{r}-0.0623 \\
(0.178)\end{array}$ & $\begin{array}{c}-0.0616 \\
(0.178)\end{array}$ \\
\hline Away_match $>1,100 \&<1,200 m$ & $\begin{array}{c}-0.0898 * \\
(0.0459)\end{array}$ & $\begin{array}{r}-0.0957 \\
(0.268)\end{array}$ & $\begin{array}{r}-0.0957 \\
(0.268)\end{array}$ & $\begin{array}{c}0.0204 \\
(0.0526)\end{array}$ & $\begin{array}{l}0.0157 \\
(0.155)\end{array}$ & $\begin{array}{l}0.0151 \\
(0.155)\end{array}$ \\
\hline Away_match $>1,200 \&<1,300 m$ & $\begin{array}{c}0.0285 \\
(0.0487)\end{array}$ & $\begin{array}{l}0.0212 \\
(0.187)\end{array}$ & $\begin{array}{l}0.0213 \\
(0.187)\end{array}$ & $\begin{array}{l}-0.0131 \\
(0.0599)\end{array}$ & $\begin{array}{c}-0.0173 \\
(0.0701)\end{array}$ & $\begin{array}{c}-0.0174 \\
(0.0700)\end{array}$ \\
\hline Away_match $>1,300 \&<1,400 m$ & $\begin{array}{c}-0.0739 \\
(0.0545) \\
\end{array}$ & $\begin{array}{r}-0.0795 \\
(0.341) \\
\end{array}$ & $\begin{array}{r}-0.0793 \\
(0.341) \\
\end{array}$ & $\begin{array}{l}-0.149 * * \\
(0.0698) \\
\end{array}$ & $\begin{array}{l}-0.153 \\
(0.106) \\
\end{array}$ & $\begin{array}{l}-0.153 \\
(0.106) \\
\end{array}$ \\
\hline Observations & 270,555 & 270,555 & 270,555 & 270,555 & 270,555 & 270,555 \\
\hline Climate controls & $\mathrm{NO}$ & YES & YES & YES & YES & YES \\
\hline Time controls & NO & YES & YES & YES & YES & YES \\
\hline Seasonal controls & NO & YES & YES & YES & YES & YES \\
\hline Derby dummy & NO & YES & YES & YES & YES & YES \\
\hline Week fixed effects & $\mathrm{NO}$ & NO & YES & NO & NO & YES \\
\hline
\end{tabular}

Note: Probit results of estimating Eq. (2). Dependent variable defined as a binary indicator for whether any crime of type $m$ (theft or assault) occurred on day $t$. Climate controls include: average rainfall, average number of sun hours, average temperature, average pressure and average wind speed. Time controls include: day of the week, holiday indicator, week of the year, weekend and month. Seasonal controls include dummies for summer (mainly September) and winter. Robust standard errors are shown in parentheses. $* * * \mathrm{p}<0.01, * * \mathrm{p}<0.05, * \mathrm{p}<0.1$. 


\section{Appendix C.}

Table C.1. OLS estimations. Effect of home and away matches on fraud counts.

\begin{tabular}{lccc}
\hline VARIABLES & $(2)$ & $(3)$ & $(4)$ \\
\hline & Fraud & Fraud & Fraud \\
Home match & $-1.181^{*}$ & $-1.273^{*}$ & -0.773 \\
& $(0.655)$ & $(0.664)$ & $(0.795)$ \\
Away match & -0.845 & -0.947 & -0.429 \\
& $(0.590)$ & $(0.602)$ & $(0.746)$ \\
Constant & $3.848^{* * *}$ & $4.622^{* * *}$ & $3.337^{* * *}$ \\
& $(0.452)$ & $(0.745)$ & $(0.735)$ \\
R-squared & 0.259 & 0.266 & 0.314 \\
Durbin-Watson (original) & 1.98 & 1.99 & 2.09 \\
Durbin-Watson (transformed) & 1.99 & 1.99 & 1.99 \\
\hline Observations & 1,215 & 1,215 & 1,215 \\
Climate controls & NO & YES & YES \\
Time controls & YES & YES & YES \\
Year fixed effects & NO & NO & YES \\
Seasonal controls & YES & YES & YES \\
Derby dummy & YES & YES & YES \\
\hline Nerb
\end{tabular}

Notes: OLS results of estimating Eq. (1) using the corrected for first-order serially-correlated residuals using the Prais-Winsten transformed regression estimator. Dependent variable fraud counts. Climate controls include: average rainfall, average number of sun hours, average temperature, average pressure and average wind speed. Time controls include: day of the week, holiday indicator, week of the year, weekend and month. Seasonal controls include dummies for summer (mainly September) and winter. Robust standard errors are shown in parentheses. $* * * \mathrm{p}<0.01, * * \mathrm{p}<0.05,{ }^{*} \mathrm{p}<0.1$. 
Table C.2. Non-cumulative rings (100 meters). Negative binomial. Fraud.

\begin{tabular}{|c|c|c|}
\hline VARIABLES & $(4)$ & $(5)$ \\
\hline Home_match $<300 m$ & - & - \\
\hline \multirow[t]{2}{*}{ Home_match $>300 \&<400 m$} & $6.18 \mathrm{e}-08$ & $3.60 \mathrm{e}-08$ \\
\hline & {$[0.000235]$} & {$[0.000176]$} \\
\hline \multirow[t]{2}{*}{ Home_match $>400 \&<500 m$} & 2.681 & 2.581 \\
\hline & [2.196] & [2.118] \\
\hline Home_match $>500 \&<600 m$ & - & - \\
\hline Home_match $>600 \&<700 m$ & - & - \\
\hline \multirow[t]{2}{*}{ Home_match $>700 \&<800 m$} & $3.27 \mathrm{e}-07$ & $1.92 \mathrm{e}-07$ \\
\hline & {$[0.000927]$} & [0.000697] \\
\hline \multirow[t]{2}{*}{ Home_match $>800 \&<900 m$} & 0.670 & 0.645 \\
\hline & {$[0.751]$} & {$[0.723]$} \\
\hline \multirow[t]{2}{*}{ Home_match $>900 \&<1,000 m$} & $1.40 \mathrm{e}-07$ & $8.17 \mathrm{e}-08$ \\
\hline & {$[0.000608]$} & {$[0.000456]$} \\
\hline \multirow[t]{2}{*}{ Home_match $>1,000 \&<1,100 m$} & $5.01 \mathrm{e}-07$ & $2.95 \mathrm{e}-07$ \\
\hline & {$[0.00115]$} & {$[0.000868]$} \\
\hline \multirow[t]{2}{*}{ Home_match $>1,100 \&<1,200 m$} & $2.99 \mathrm{e}-07$ & $1.76 \mathrm{e}-07$ \\
\hline & {$[0.000396]$} & {$[0.000298]$} \\
\hline \multirow[t]{2}{*}{ Home_match $>1,200 \&<1,300 m$} & $1.288 \mathrm{e}+06$ & $2.018 \mathrm{e}+06$ \\
\hline & {$[9.177 \mathrm{e}+08]$} & {$[1.728 \mathrm{e}+09]$} \\
\hline \multirow{2}{*}{ Home_match $>1,300 \&<1,400 m$} & $4.06 \mathrm{e}-07$ & $2.39 \mathrm{e}-07$ \\
\hline & {$[0.000728]$} & {$[0.000548]$} \\
\hline Away_match $<300 m$ & - & - \\
\hline \multirow[t]{2}{*}{ Away_match $>300 \&<400 m$} & 0.605 & 0.598 \\
\hline & {$[0.496]$} & {$[0.491]$} \\
\hline \multirow[t]{2}{*}{ Away_match $>400 \&<500 m$} & 0.405 & 0.400 \\
\hline & {$[0.371]$} & {$[0.366]$} \\
\hline Away_match $>500 \&<600 m$ & - & - \\
\hline Away_match $>600 \&<700 m$ & - & - \\
\hline \multirow[t]{2}{*}{ Away_match $>700 \&<800 m$} & 1.190 & 1.176 \\
\hline & [1.461] & [1.444] \\
\hline \multirow[t]{2}{*}{ Away_match $>800 \&<900 m$} & 0.455 & 0.449 \\
\hline & [0.349] & {$[0.345]$} \\
\hline \multirow[t]{2}{*}{ Away_match $>900 \&<1,000 m$} & 0.597 & 0.590 \\
\hline & {$[0.846]$} & {$[0.836]$} \\
\hline \multirow[t]{2}{*}{ Away_match $>1,000 \&<1,100 m$} & 4.203 & 4.153 \\
\hline & {$[4.505]$} & [4.452] \\
\hline \multirow[t]{2}{*}{ Away_match $>1,100 \&<1,200 m$} & $0.119 *$ & $0.117 *$ \\
\hline & {$[0.130]$} & [0.129] \\
\hline \multirow[t]{2}{*}{ Away_match $>1,200 \&<1,300 m$} & 0.0308 & 0.0309 \\
\hline & {$[97.25]$} & [123.3] \\
\hline \multirow[t]{2}{*}{ Away_match $>1,300 \&<1,400 m$} & 0.295 & 0.292 \\
\hline & {$[0.362]$} & {$[0.358]$} \\
\hline Observations & 111,435 & 111,435 \\
\hline Climate controls & YES & YES \\
\hline Time controls & YES & YES \\
\hline Seasonal controls & YES & YES \\
\hline Derby dummy & YES & YES \\
\hline Week fixed effects & NO & YES \\
\hline Day fixed effects & NO & NO \\
\hline Census tract fixed effects & YES & YES \\
\hline
\end{tabular}

Notes: Negative binomial results of estimating Eq. (2). Dependent variable fraud counts. Some rings have no fraud counts in the period analyzed. Climate controls include: average rainfall, average number of sun hours, average temperature, average pressure and average wind speed. Time controls include: day of the week, holiday indicator, week of the year, weekend and month. Seasonal controls include dummies for summer (mainly September) and winter. Coefficients reported as incidence rate ratios. p-values in square brackets. $* * * \mathrm{p}<0.01, * * \mathrm{p}<0.05, * \mathrm{p}<0.1$. 


\section{Appendix D}

Table D.1. Buffers from the FCB Stadium. Census tracts included in each ring.

\begin{tabular}{|lc|}
\hline \multicolumn{1}{|c|}{ Distance from FC Barcelona Stadium } & \# of census tracts \\
\hline$<300 m$ & 2 \\
$>300 m \&<400 m$ & 4 \\
$>400 m \&<500 m$ & 6 \\
$>500 m \&<600 m$ & 4 \\
$>600 m \&<700 m$ & 4 \\
$>700 m \&<800 m$ & 7 \\
$>800 m \&<900 m$ & 9 \\
$>900 m \&<1,000 m$ & 7 \\
$>1,000 m \&<1,100 m$ & 10 \\
$>1,100 m \&<1,200 m$ & 10 \\
$>1,200 m \&<1,300 m$ & 8 \\
$>1,300 m \&<1,400 m$ & 7 \\
\hline
\end{tabular}

Figure D.1. Locational maps.

Area depicted in Figures D.2 \&D.3.

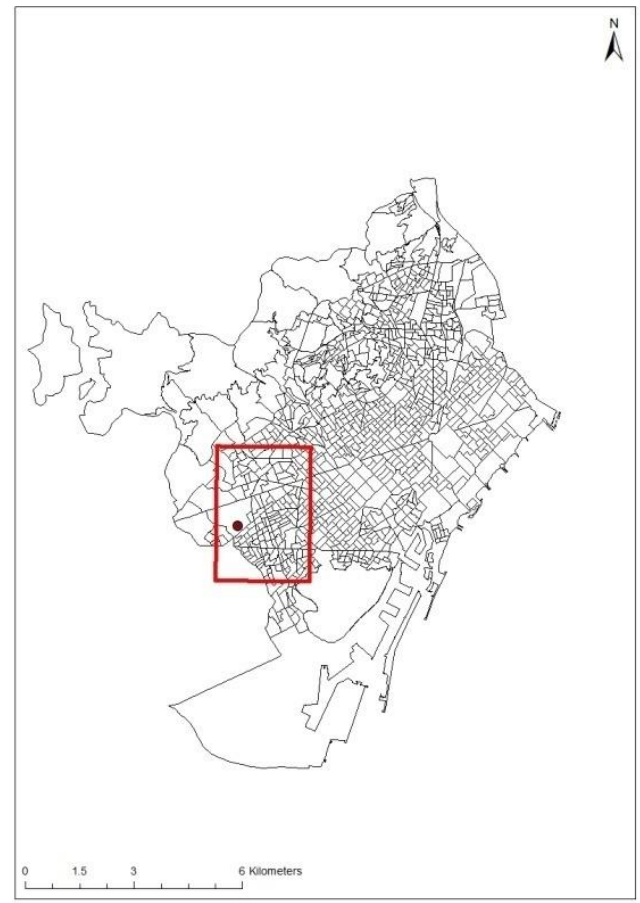

Cumulative rings (buffers) around FCB Stadium

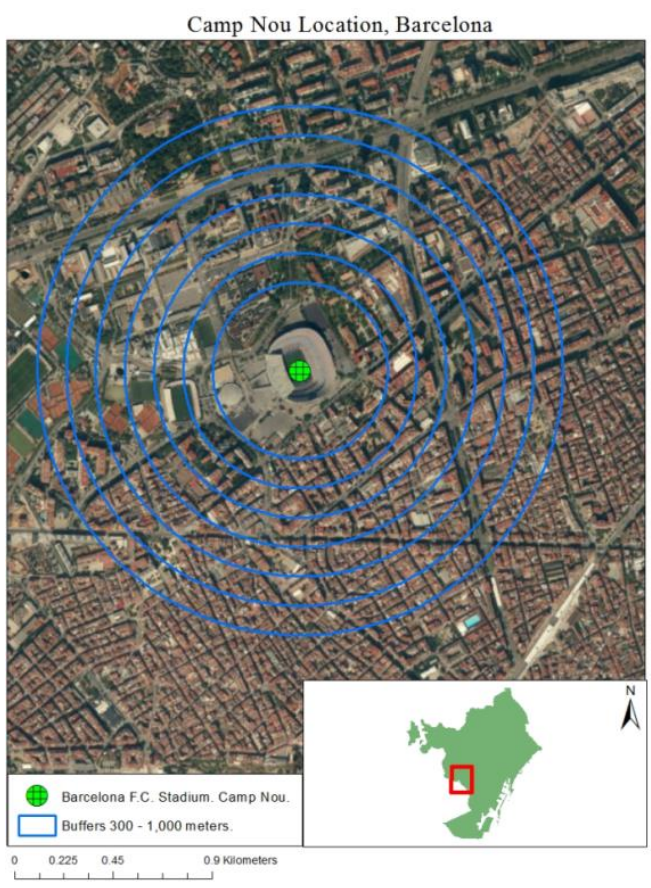


Figure D.2. Kernel density functions around FCB Stadium for thefts when the club plays at home (top panel), away (bottom panel) \&days with no football match.

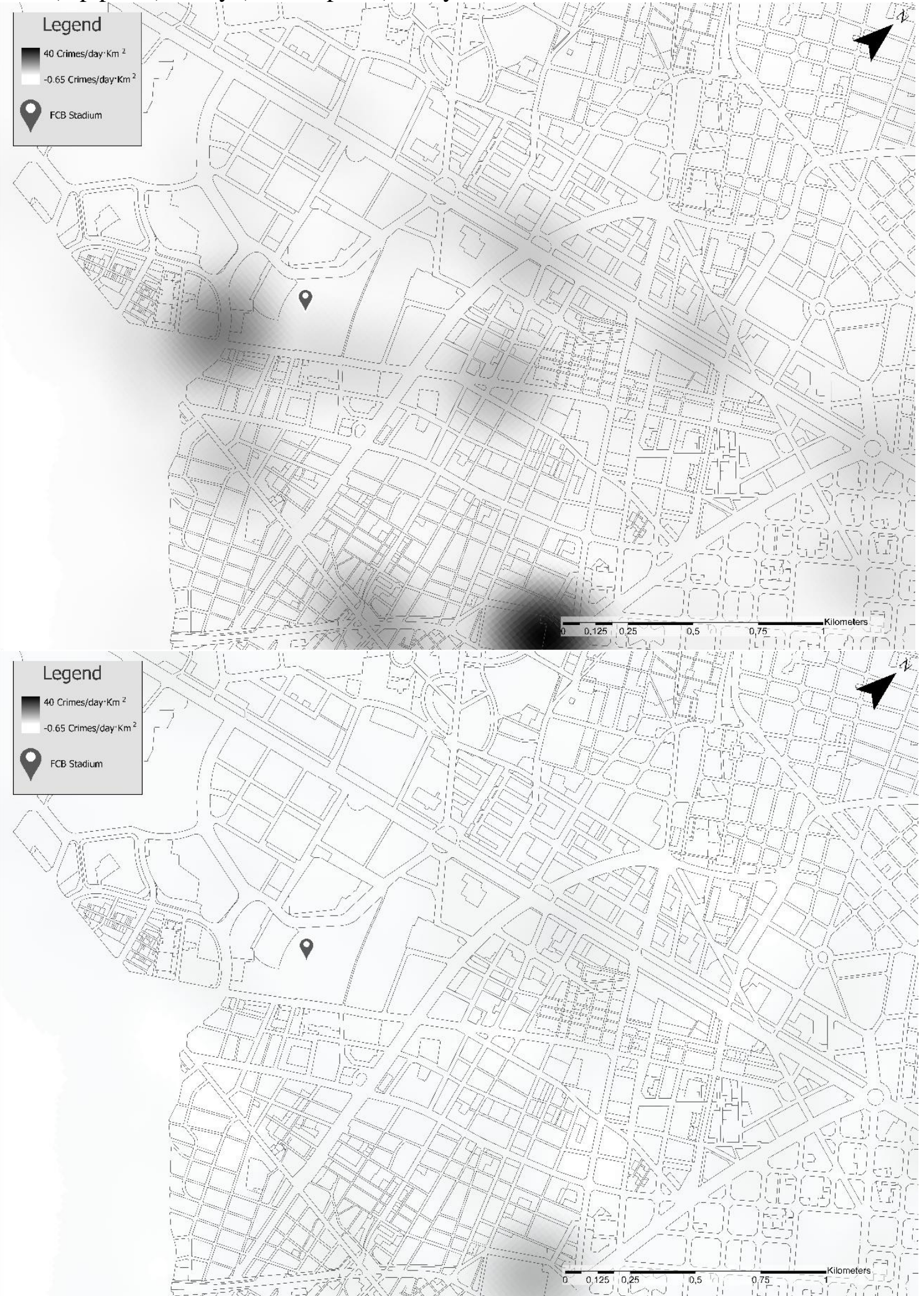

Note: Quadratic kernel functions. The representation is the density function per square km using natural breaks so as to identify outliers clearly. Bandwidths are set at 300 meters for both thefts and assaults. Cell size is set at 20 meters to show as much detail as possible. 
Figure D.3. Kernel density functions around FCB Stadium for assaults when the club plays at home (top panel), away (bottom panel) \&days with no football match.

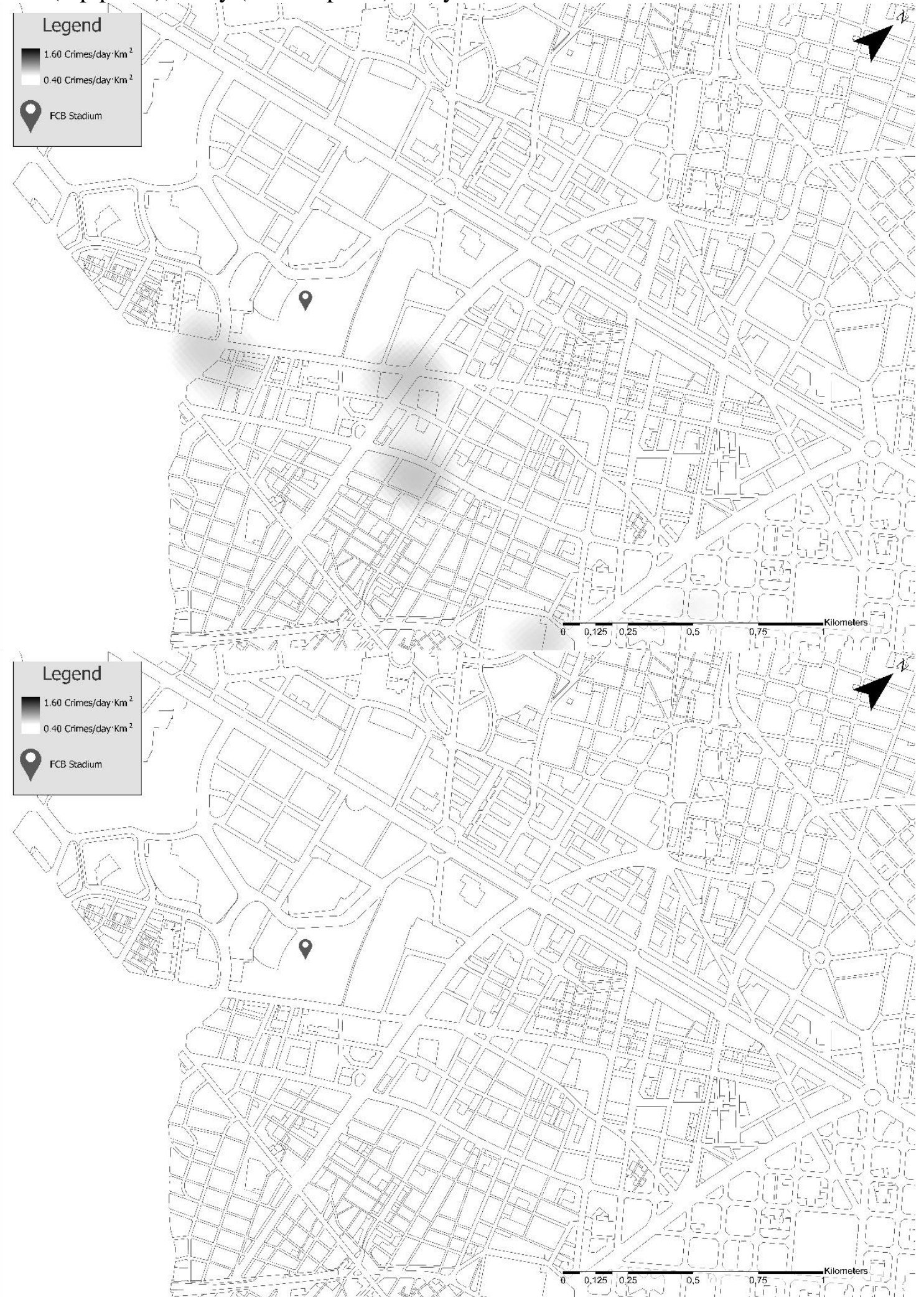

Note: Quadratic kernel functions. The representation is the density function per square km using natural breaks so as to identify outliers clearly. Bandwidths are set at 300 meters for both thefts and assaults. Cell size is set at 20 meters to show as much detail as possible. 


\section{Appendix E}

Figure E.1. Negative binomial estimates for non-cumulative rings (150 meters)
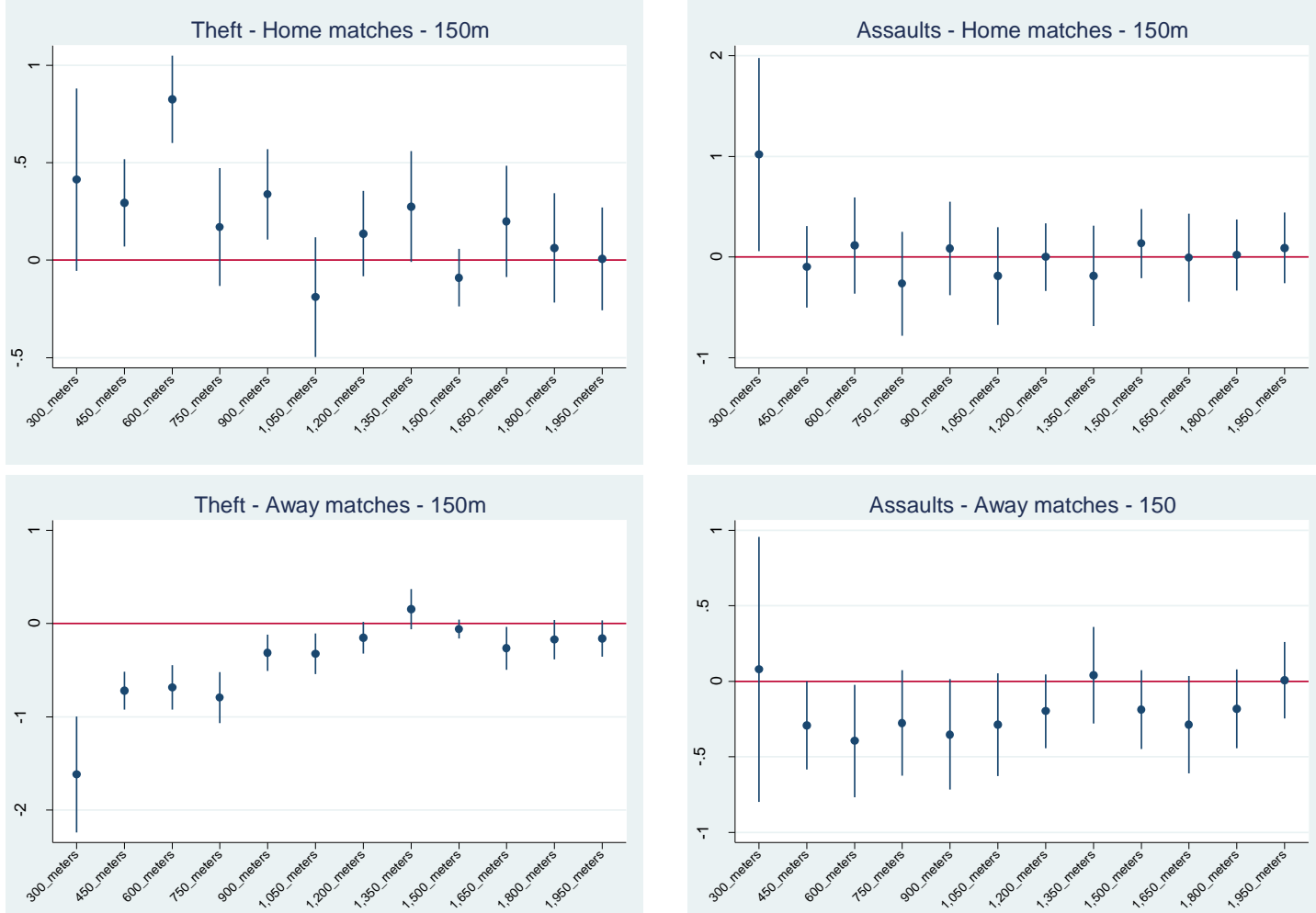

Notes: Graphical representation of the negative binomial results of estimating Eq. (2). Dependent variable crime counts. Climate controls include: average rainfall, average number of sun hours, average temperature, average pressure and average wind speed. Time controls include: day of the week, holiday indicator, week of the year, weekend and month. Seasonal controls include dummies for summer (mainly September) and winter. Coefficients reported as incidence rate ratios. 
Figure E.2. Negative binomial estimates for non-cumulative rings (200 meters)
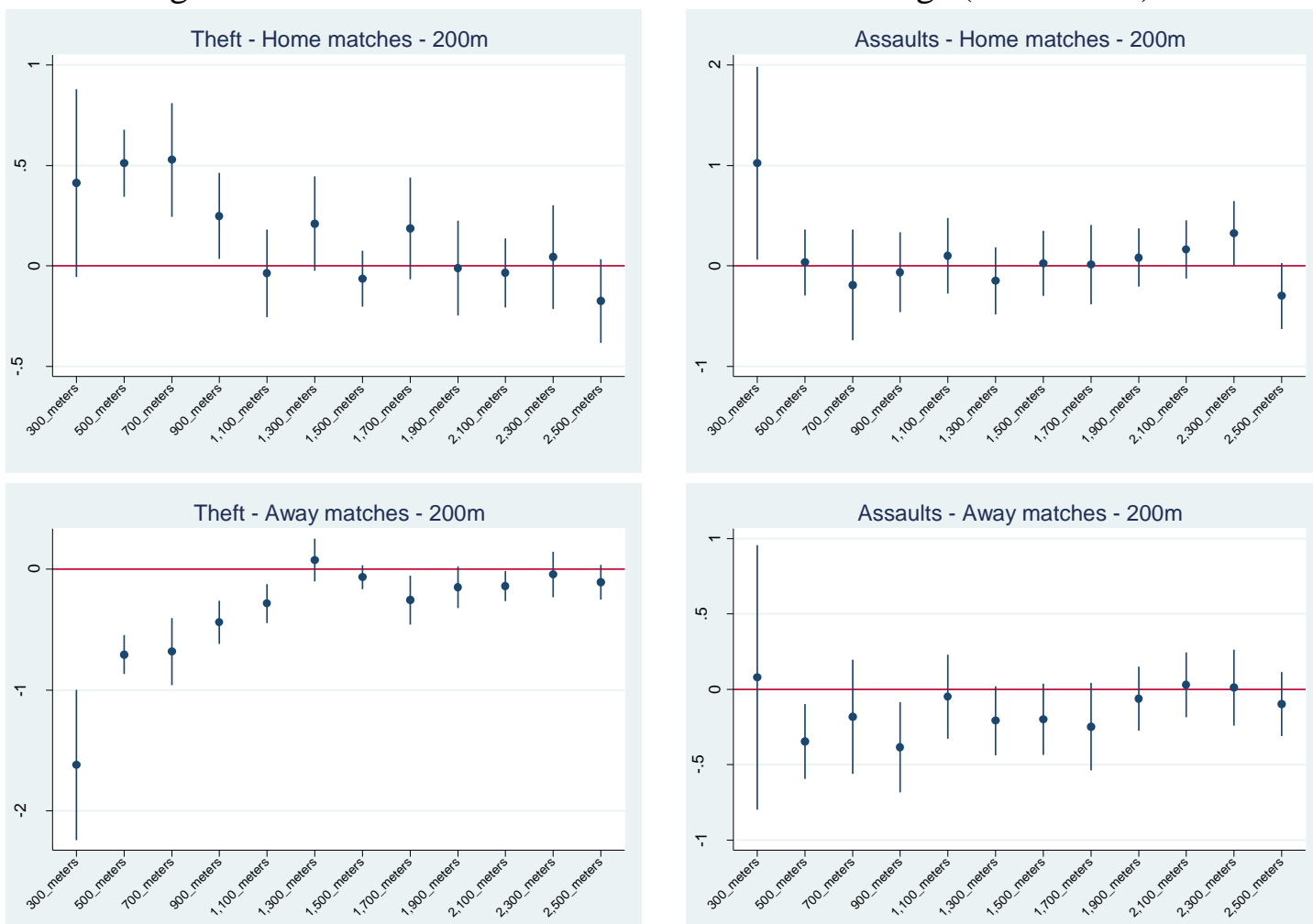

Notes: Graphical representation of the negative binomial results of estimating Eq. (2). Dependent variable crime counts. Climate controls include: average rainfall, average number of sun hours, average temperature, average pressure and average wind speed. Time controls include: day of the week, holiday indicator, week of the year, weekend and month. Seasonal controls include dummies for summer (mainly September) and winter. Coefficients reported as incidence rate ratios. 